\title{
Effects of Trade Wind Strength on Airflow and Cloudiness over Oahu
}

\author{
Feng Hsiao, ${ }^{\text {a }}$ Yi-Leng Chen, ${ }^{a}$ Hiep VAn NGuyen, ${ }^{b}$ David Eugene Hitzl, ${ }^{\text {a }}$ And Robert Ballard ${ }^{c}$ \\ ${ }^{a}$ Department of Atmospheric Sciences, University of Hawai'i at Mānoa, Honolulu, Hawai $i$ \\ ${ }^{\mathrm{b}}$ Applied Geophysics Center, Institute of Geophysics, Vietnam Academy of Science and Technology, Hanoi, Vietnam \\ ${ }^{\mathrm{c}}$ National Weather Service Honolulu Forecast Office, Honolulu, Hawai' $i$
}

(Manuscript received 7 December 2020, in final form 12 June 2021)

\begin{abstract}
Satellite observations and high-resolution modeling during July-August 2013 are used to study the effects of trade wind strength on island wake circulations and cloudiness over Oahu, Hawaii. Oahu comprises two northwest-southeast-orientated mountain ranges: the Waianae Range $(\sim 1227 \mathrm{~m})$ along the western leeside coast and the Koolau Range ( $\sim 944 \mathrm{~m})$ along the eastern windward coast. At night, the flow deceleration of the incoming northeasterly trade winds on the eastern windward side is more significant when trades are stronger. In the afternoon hours, effective albedo and simulated cloud water are greater over the Koolau Range when trades are stronger, and clouds are advected downstream by the trade winds aloft. Over the Waianae Range, orographic clouds are more significant when trades are weaker due to less moisture removal by orographic precipitation over the Koolau Range and the development of both upslope flow on the eastern slope and upslope/sea-breeze flow along the western coast, the latter of which brings in warm, moist air from the ocean. When trades are weaker, cloudiness off the western leeside coast is more extensive and originates from orographic cloud development over the Waianae Range, which drifts downstream due to a combination of trade winds and the easterly return flow aloft. The latter is associated with the low-level sea-breeze/upslope flow.
\end{abstract}

KEYWORDS: Sea breezes; Diurnal effects; Orographic effects

\section{Introduction}

The island of Oahu (Fig. 1), with a horizontal area of $1545 \mathrm{~km}^{2}$, is dominated by two volcanic mountain ranges oriented in a northwest-southeast direction: the Waianae Range along the western leeside coast and the Koolau Range along the northeastern windward coast, with a broad "valley" (the central Oahu plain) between them (Fig. 1). The Waianae Range has two peaks: Mount Kaala (1227 m) over the northern part of the range and Mount Palikea ( $944 \mathrm{~m}$ ) over the southeastern arm. For the Koolau Range, the highest peak is $946 \mathrm{~m}$.

Despite its relatively small size, a pronounced diurnal cycle over Oahu is evident under summer trade wind conditions (Leopold 1948). Most stations over the Koolau Range have an early morning/nocturnal rainfall maximum caused by orographic blocking/lifting and cloud-top radiative cooling (Hartley and Chen 2010; Van Nguyen et al. 2010). With mountaintops below the trade wind inversion $(\sim 1.9 \mathrm{~km}$, Winning et al. 2017), afternoon sea-breeze/onshore flows occur over the western leeside coast, especially under weak wind conditions (Hartley and Chen 2010; Van Nguyen et al. 2010; Hsiao et al. 2020). At night, over the Waianae Range, combined downslope-katabatic winds are present over the western leeside slopes and extend downstream off the leeside coast with mountain winds along the eastern windward slopes. Furthermore, a hydraulic jump above and downstream of the Waianae Range is more pronounced at night than in the afternoon (Van Nguyen et al. 2010). Along the western leeside coast of Oahu, rainfall is

Corresponding author: Yi-Leng Chen, yileng@hawaii.edu infrequent with an early afternoon maximum hourly rainfall frequency of $\sim 10 \%$ under weak wind conditions due to the development of sea-breeze/upslope flows (Hartley and Chen 2010).

Clouds over island wake zones have been observed and studied around the world, including Anegada, British Virgin Islands (Malkus 1963); Nantucket, Massachusetts (Malkus and Bunker 1952); the Pacific island of Guadalupe (Dorman 1994); Nauru (Nordeen et al. 2001); Hawaii (Yang et al. 2008b,c); Lesser Antilles (Kirshbaum and Fairman 2015); and Bermuda (Johnston et al. 2018). Yang et al. (2008a,b,c) studied diurnal variations of cloudiness in the wake zone of Kauai, Niihau, and Oahu using satellite data. With mountaintops below the trade wind inversion, Yang et al. (2008b,c) attributed the afternoon cloudiness in the wake zone of Kauai and Oahu to a combination of leeside convergence of islanddeflected airflows and warm-air advection from the island to the wake zone. They directly link warm advection to enhanced wake convergence and cloudiness in the wake zone. The warm advection from the island interior to the leeside offshore during the daytime increases the air temperature in the wake zone and enhances the low-level convergence, leading to an increase in cloudiness.

In contrast to the thermal advection mechanism proposed by Yang et al. (2008b,c), there are studies showing the importance of temperature gradients in controlling the strength of thermally driven circulations in the leeside area (e.g., Crook 2001; Van Nguyen et al. 2010; Hartley and Chen 2010; Jury and Chiao 2013; Kirshbaum and Fairman 2015). In model sensitivity tests (Van Nguyen et al. 2010), the daytime westerly onshore flow along the western leeside coast of Oahu is shown to be thermally driven and related to land surface 


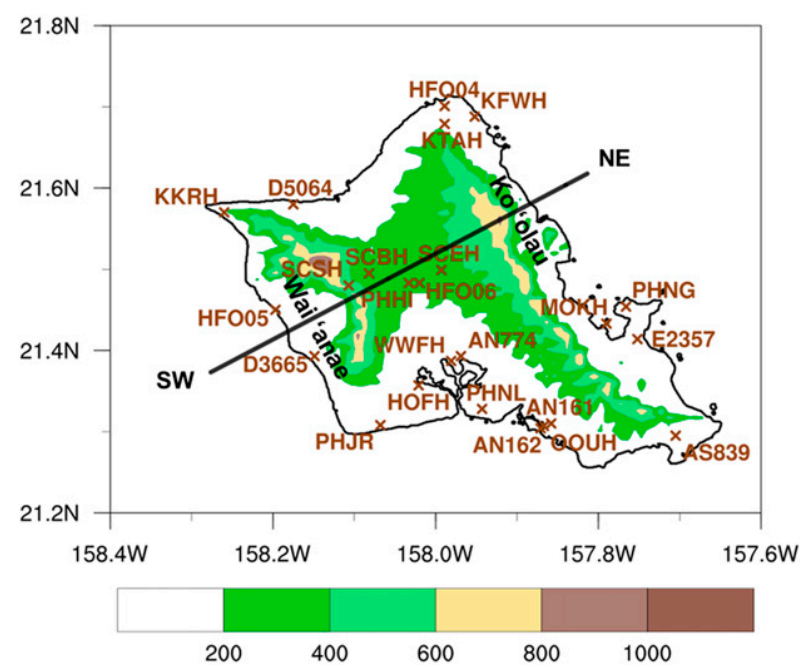

FIG. 1. The island of Oahu. Elevation contours are in 200-m intervals. A brown $\times$ represents the surface weather stations (see Table 1 for station information) for 34 trade wind days during Jul-Aug 2013. A solid line indicates the position for cross-section analysis.

heating superimposed by latent heat release from persistent orographic precipitation over the Koolau and Waianae Ranges. Hartley and Chen (2010) found that the westerly onshore flow along the leeside coast during the daytime is more pronounced under relatively weak wind conditions.
In this study, the impact of trade wind strength on the leeside circulations and cloudiness offshore, especially during the daytime, will be further investigated using both observations and numerical simulations. When trade winds are stronger, they may advect warm air from the island interior downstream more significantly and couple with stronger descending airflow in the leeside wake zone, reducing temperature gradients between the island and the adjacent ocean, and thus weakening thermal circulations along the leeside coast, and affecting thermodynamic properties and cloudiness within the wake zone. The high-resolution $(1.5 \mathrm{~km})$ island-scale simulations from the Weather Research and Forecast Advanced Research Model (WRF-ARW; Skamarock et al. 2008) are used to examine the mechanisms involved in the airflows and clouds in the wake zone of Oahu in comparison with satellite observations. The impacts of trade wind strength on airflows, temperature, moisture, and cloudiness over Oahu at different times of the diurnal heating cycle, especially off the leeside coast in the afternoon hours, are investigated. The data and methodology, including model configuration and verifications, are given in section 2. Results from satellite observations and model simulations concerning the impacts of trade wind speed on airflow and cloudiness in the early morning and afternoon hours are presented in section 3. Finally, a summary is given in section 4 .

\section{Data and methodology}

\section{a. Data}

The National Centers for Environmental Prediction (NCEP) Climate Forecast System, version 2 (CFSv2; Saha et al. 2011), is a

TABLE 1. The station ID, network, temporal resolution, and geolocation for each of the 24 weather stations.

\begin{tabular}{|c|c|c|c|c|c|}
\hline Station code & Network & Temporal resolution & Lon $\left(^{\circ}\right)$ & Lat $\left(^{\circ}\right)$ & Elevation $(\mathrm{m})$ \\
\hline AN161 & AIRNOW & Hourly & -157.86 & 21.31 & 15.9 \\
\hline AN162 & AIRNOW & Hourly & -157.87 & 21.30 & 3.1 \\
\hline AN774 & AIRNOW & Hourly & -157.97 & 21.39 & 14.9 \\
\hline AS839 & APRSWXNET/CWOP & $5 \mathrm{~min}$ & -157.71 & 21.30 & 131.1 \\
\hline D3665 & APRSWXNET/CWOP & $15 \mathrm{~min}$ & -158.15 & 21.39 & 14.9 \\
\hline D5064 & APRSWXNET/CWOP & $15 \mathrm{~min}$ & -158.18 & 21.58 & 0.9 \\
\hline E2357 & APRSWXNET/CWOP & $10 \min$ & -157.75 & 21.41 & 27.1 \\
\hline HFO04 & HNLWFO & Hourly & -157.99 & 21.70 & 4.6 \\
\hline HFO05 & HNLWFO & Hourly & -158.20 & 21.45 & 1.5 \\
\hline HFO06 & HNLWFO & Hourly & -158.02 & 21.48 & 264.3 \\
\hline HOFH & RAWS & Hourly & -158.02 & 21.36 & 1.5 \\
\hline KFWH & RAWS & Hourly & -157.95 & 21.69 & 1.5 \\
\hline KKRH & RAWS & Hourly & -158.26 & 21.57 & 288.7 \\
\hline КTAH & RAWS & Hourly & -157.99 & 21.68 & 181.7 \\
\hline MOKH & NOS-NWLON & $6 \mathrm{~min}$ & -157.79 & 21.43 & 4.9 \\
\hline OOUH & NOS-NWLON & $6 \mathrm{~min}$ & -157.87 & 21.31 & 0.0 \\
\hline PHHI & NWS & Hourly & -158.03 & 21.48 & 255.1 \\
\hline PHJR & NWS & Hourly & -158.07 & 21.31 & 10.1 \\
\hline PHNG & NWS & Hourly & -157.77 & 21.45 & 4.9 \\
\hline PHNL & NWS & Hourly & -157.94 & 21.33 & 3.1 \\
\hline $\mathrm{SCBH}$ & RAWS & Hourly & -158.08 & 21.50 & 298.7 \\
\hline SCEH & RAWS & Hourly & -157.99 & 21.50 & 381.0 \\
\hline $\mathrm{SCSH}$ & RAWS & Hourly & -158.11 & 21.48 & 453.9 \\
\hline WWFH & RAWS & Hourly & -157.98 & 21.39 & 1.5 \\
\hline
\end{tabular}



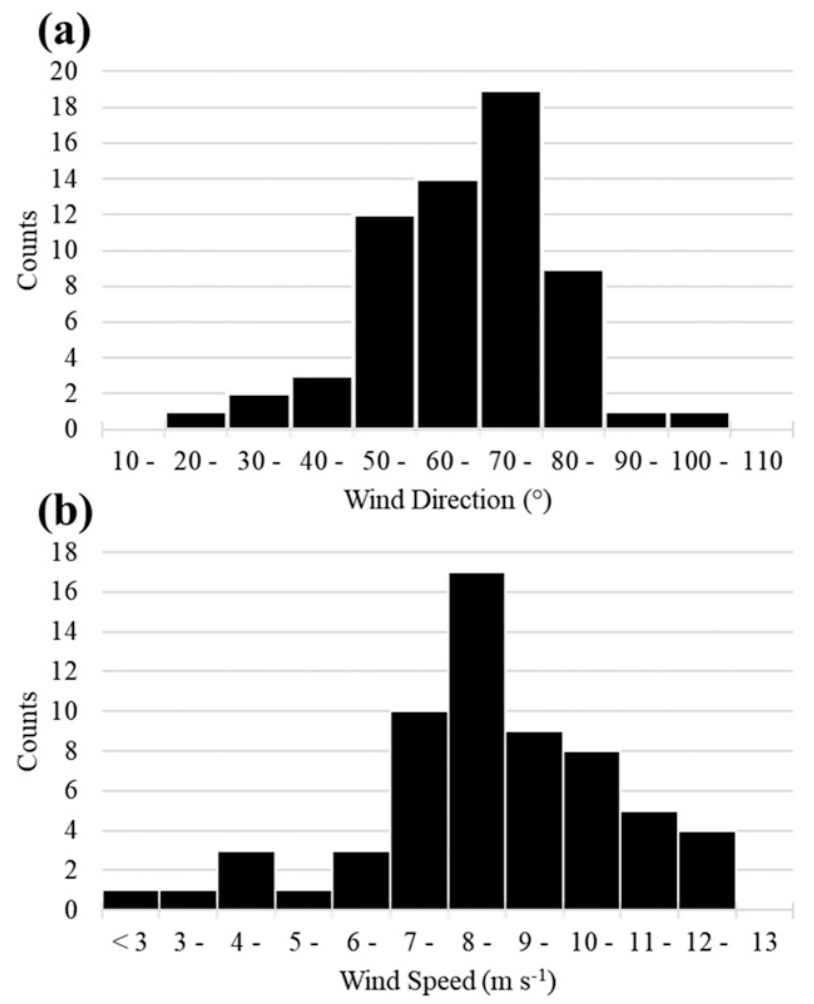

FIG. 2. Histogram of (a) wind direction and (b) wind speed from CFSv2 at the upstream point during July-August 2013.

coupled dynamical model with initial conditions provided by data assimilation. The 6-hourly CFSv2 $0.5^{\circ} \times 0.5^{\circ}$ gridded data are used in this study as input for the high-resolution mesoscale model and for assessing wind velocity at an upstream point.

In terms of observational data, the Geostationary Operational Environmental Satellite-15 (GOES-15) effective albedo (or reflectance factor) from the visible channel is used to depict the cloudiness after sunrise. The effective albedo has high temporal ( $\sim 30 \mathrm{~min})$ and spatial $(\sim 1 \mathrm{~km})$ resolution and its values lie between 0 and 1 . A value of 1 corresponds to the radiance of a perfectly reflecting diffuse surface illuminated at normal incidence when the sun is at its annual-average distance from Earth (Weinreb et al. 1997). Surface winds, air temperature, and relative humidity from the MesoWest cooperative network data archive (Horel et al. 2002) were quality controlled using MesoWest data quality ratings (Splitt and Horel 1998), with further subjective checks for spatial and temporal consistency. Some stations with unrealistic observations [e.g., very high temperature $\left(>30^{\circ} \mathrm{C}\right)$ at 1000 local solar time (LST $=$ UTC $-10 \mathrm{~h}$ ) and weaker surface wind compared to stations nearby were removed manually. MesoWest observations typically represent averages over the reporting interval, which can vary from $5 \mathrm{~min}$ to $1 \mathrm{~h}$ (Horel et al. 2002). The stations with observations within $20 \mathrm{~min}$ of the nearest verification times were used to validate model results (Fig. 1, brown $\times$ ). The respective network, temporal resolution, and geolocation of the 24 stations are listed in
TABLE 2. A list of the eight weak and eight strong trade wind days. The wind speed and direction at the upstream point of Oahu $\left(21.5^{\circ} \mathrm{N}, 157.5^{\circ} \mathrm{W}\right)$ are daily averages from CFSv2 analysis.

\begin{tabular}{llcc}
\hline \hline & Date & Wind speed $\left(\mathrm{m} \mathrm{s}^{-1}\right)$ & Wind direction $\left(^{\circ}\right)$ \\
\hline Weak trade & 23 Jul & 4.2 & 75.0 \\
& 30 Aug & 5.6 & 62.9 \\
& 4 Jul & 6.3 & 72.3 \\
23 Aug & 6.6 & 88.0 \\
& 26 Jul & 6.8 & 73.4 \\
25 Jul & 6.9 & 77.7 \\
8 Aug & 7.0 & 77.0 \\
7 Aug & 7.1 & 75.4 \\
Strong trade & $16 \mathrm{Aug}$ & 9.5 & 76.6 \\
& 15 Aug & 9.6 & 83.7 \\
& 26 Aug & 9.7 & 76.3 \\
27 Aug & 9.7 & 82.4 \\
11 Aug & 9.8 & 81.1 \\
18 Aug & 10.3 & 79.5 \\
17 Aug & 10.8 & 75.4 \\
10 Jul & 12.2 & 83.5 \\
\hline
\end{tabular}

Table 1. Anemometers at RAWS network stations are installed at $6 \mathrm{~m}$ above ground. The anemometer at station OOUH is $7.1 \mathrm{~m}$ above ground. Winds at other stations are measured at $10 \mathrm{~m}$. A correction factor of 1.086 (Bradshaw et al. 2003) was applied to the RAWS stations and OOUH to convert the 6- and 7.1-m wind speeds to 10-m values (Hartley and Chen 2010).

\section{b. Strong and weak trade categories}

In this study, July-August 2013 is used to represent typical summer conditions. The spatial distribution of total precipitable

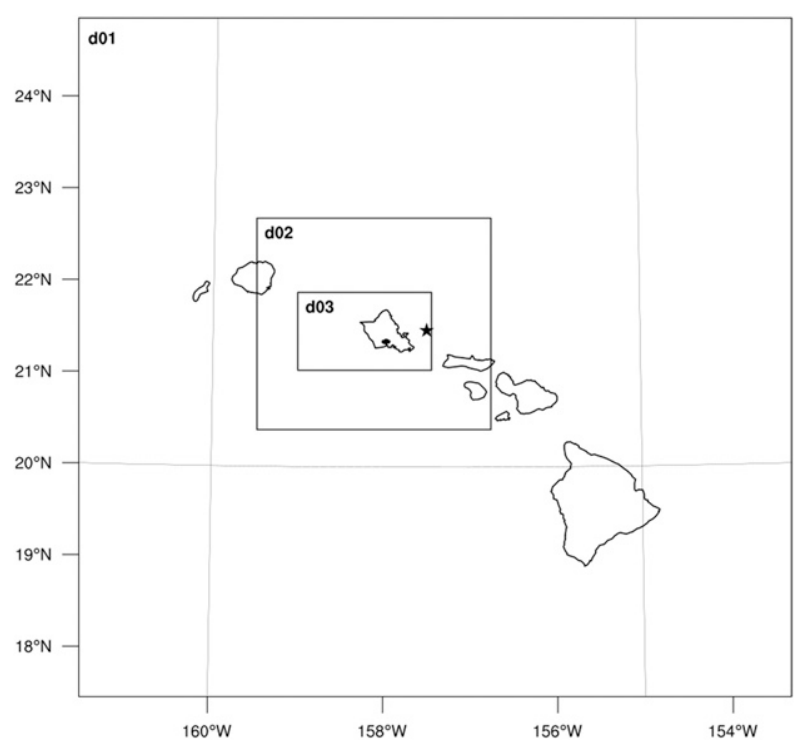

FIG. 3. Three nesting domains employed in the simulations with grid sizes of $13.5,4.5$, and $1.5 \mathrm{~km}$, respectively. The black star represents the upstream point for Oahu used in this study $\left(21.5^{\circ} \mathrm{N}, 157.5^{\circ} \mathrm{W}\right)$. 
(a)

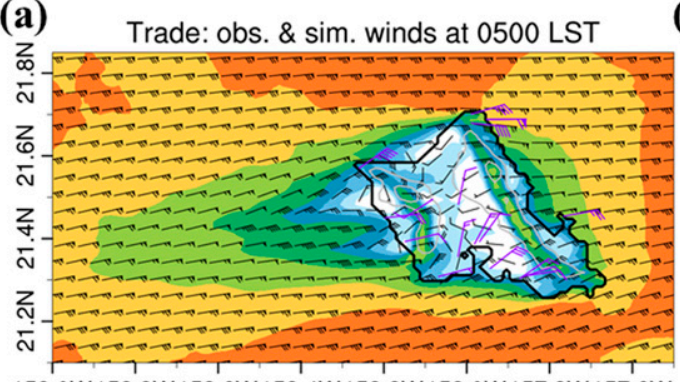

159.0W 158.8W158.6W158.4W 158.2W 158.0W 157.8W 157.6W

(c)

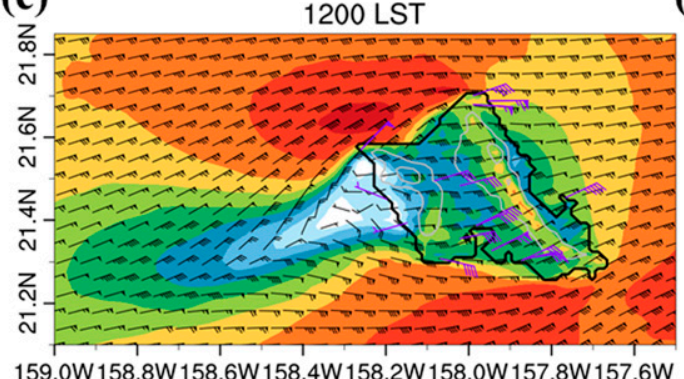

(f)

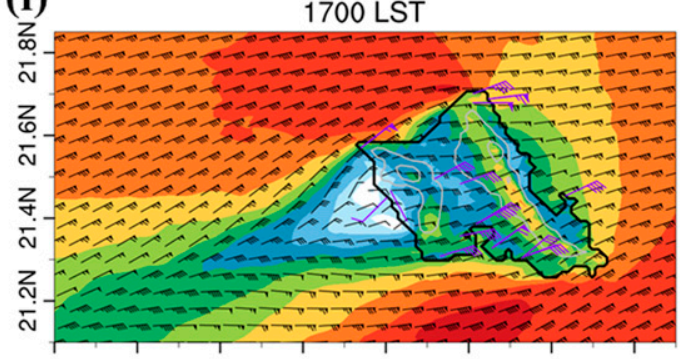

159.0W158.8W158.6W158.4W 158.2W158.0W157.8W157.6W

$\begin{array}{llllllllll}1 & 2 & 3 & 4 & 5 & 6 & 7 & 8 & 9 & 10\end{array}$ (b)

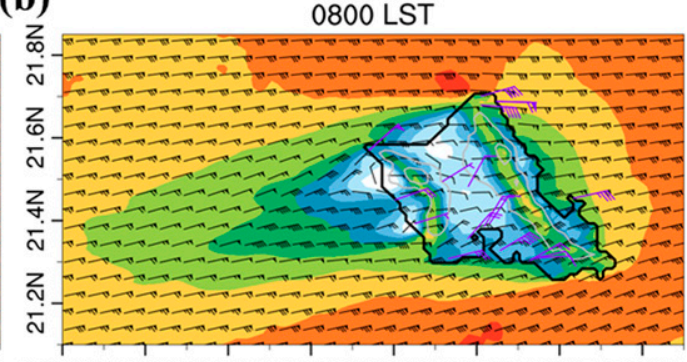

159.0W158.8W158.6W158.4W 158.2W 158.0W157.8W157.6W

(d)

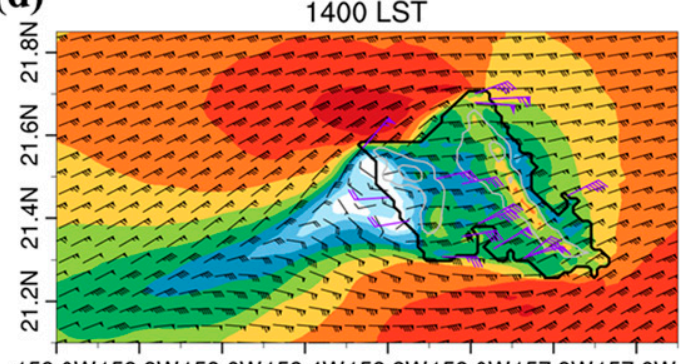

159.0W 158.8W158.6W158.4W 158.2W 158.0W 157.8W157.6W

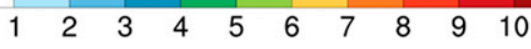

FIG. 4. Composite analysis of simulated surface wind $\left(\mathrm{m} \mathrm{s}^{-1}\right.$; black barbs and color shading) and observed surface wind ( $\mathrm{m} \mathrm{s}^{-1}$; purple barbs) for the 34 trade wind days at (a) 0500, (b) 0800, (c) 1200, (d) 1400, and (e) 1700 LST. One pennant is $5 \mathrm{~m} \mathrm{~s}^{-1}$, a full barb is $1 \mathrm{~m} \mathrm{~s}^{-1}$, a half barb is $0.5 \mathrm{~m} \mathrm{~s}^{-1}$, and a circle denotes calm wind. water (TPW) during July-August 2013 is similar to the longterm July-August mean during 1979-2015. The spatial correlation over the Hawaiian Islands $\left(16-26^{\circ} \mathrm{N}, 148-164^{\circ} \mathrm{W}\right)$ between the 2013 summer seasonal averaged TPW and the long-term summer seasonal (1979-2015) averaged TPW is 0.97 . The trade winds during July-August 2013 were slightly weaker $\left(\sim 1 \mathrm{~m} \mathrm{~s}^{-1}\right)$ than the 2-month composite of 1979-2015 (not shown). The El Niño-Southern Oscillation (ENSO) was in a neutral phase during the summer of 2013 (NOAA/CPC 2020).

The daily mean wind data at an upstream point of Oahu $\left(21.5^{\circ} \mathrm{N}, 157.5^{\circ} \mathrm{W}\right)$ (Hsiao et al. 2020) from CFSv2 analysis (every $6 \mathrm{~h}$ ) are used to determine the upstream prevailing wind conditions for each day. Histograms of daily mean wind direction and daily mean wind speed during JulyAugust 2013 show that the prevailing wind direction is from $60^{\circ}$ to $90^{\circ}$ with wind speeds from 6 to $9 \mathrm{~m} \mathrm{~s}^{-1}$ (Fig. 2). Days with wind directions between $60^{\circ}$ and $90^{\circ}$ and wind speed $>3 \mathrm{~m} \mathrm{~s}^{-1}$, in the absence of synoptic disturbances over the central Pacific (tropical storms, upper-level lows/troughs, and shear lines associated with midlatitude cold fronts) (Hartley and Chen 2010), during the 2-month period are classified as trade wind days (34 days total). The 8 days ( $\sim 25 \%$ of the total trade wind days) with the strongest trade wind speeds are classified as strong trade wind days, with wind speeds from 9.5 to $12.2 \mathrm{~m} \mathrm{~s}^{-1}$. The 8 days with the weakest trade wind speed are classified as weak trade wind days, with wind speed from 4.2 to $7.1 \mathrm{~m} \mathrm{~s}^{-1}$. The mean wind speeds for strong and weak trade categories are 10.2 and $6.3 \mathrm{~m} \mathrm{~s}^{-1}$, respectively. The dates of the strong and weak trade wind days are listed in Table 2.

The dynamics of mechanically forced flows over an isolated mountain may be explained with the nondimensional mountain height $(\hat{h}=N h / U$, where $U$ is the upstream wind speed, $N$ is the Brunt-Väisälä frequency, and $h$ is the mountain height) (Smolarkiewicz et al. 1988; Smith 1989; and others). The $N$ averaged below the $1000 \mathrm{~m}$ level at the upstream point for both the strong and weak trade categories is $\sim 0.01$. The mean values of $U / N$ for the strong and weak trade categories are 1020 and $630 \mathrm{~m}$, respectively. 
TABLE 3. Error statistics of surface temperature and surface relative humidity for model points corresponding to 18 Oahu weather stations during the 34 trade wind days from July to August 2013.

\begin{tabular}{lccccccc}
\hline \hline & \multicolumn{3}{c}{$T\left({ }^{\circ} \mathrm{C}\right)$} & & \multicolumn{3}{c}{ RH $(\%)$} \\
\cline { 2 - 4 } \cline { 7 - 8 } Station code & Bias & MAE & RMSE & & Bias & MAE & RMSE \\
\hline AS839 & -0.7 & 0.9 & 1.2 & & 0.4 & 4.1 & 5.2 \\
D3665 & -0.1 & 1.0 & 1.3 & & 1.6 & 8.6 & 10.2 \\
D5064 & 0.7 & 1.3 & 1.6 & & - & - & - \\
E2357 & - & - & - & & 3.4 & 6.0 & 7.6 \\
HOFH & -0.7 & 1.3 & 1.6 & & 3.6 & 9.7 & 11.2 \\
KFWH & -1.0 & 1.1 & 1.3 & & 6.5 & 7.2 & 8.4 \\
KKRH & -0.7 & 1.1 & 1.3 & & 4.5 & 8.0 & 9.8 \\
KTAH & -1.5 & 1.7 & 1.9 & & -1.7 & 5.6 & 7.3 \\
MOKH & -0.9 & 1.1 & 1.3 & & - & - & - \\
OOUH & -0.2 & 1.1 & 1.3 & & - & - & - \\
PHHI & -0.1 & 1.0 & 1.3 & & 4.4 & 7.9 & 9.7 \\
PHJR & 0.1 & 0.8 & 1.0 & & 5.4 & 7.6 & 9.0 \\
PHNG & -0.4 & 1.2 & 1.5 & & 5.3 & 7.1 & 9.1 \\
PHNL & -0.2 & 0.7 & 0.9 & & 7.5 & 8.8 & 10.2 \\
SCBH & -0.7 & 1.3 & 1.6 & & - & - & - \\
SCEH & - & - & - & -0.7 & 7.0 & 9.4 \\
SCSH & -0.5 & 1.2 & 1.6 & & - & - & - \\
WWFH & -0.2 & 1.1 & 1.4 & & 5.4 & 7.7 & 9.3 \\
\hline
\end{tabular}

With $U / N$ comparable to or smaller than $h$, orographic blocking with upstream deceleration is likely for both strong and weak wind categories. However, under weak trades, with $U / N<h$, it is unlikely that the incoming trade winds at low levels will move over the Koolau Range with peaks $\sim 944 \mathrm{~m}$.

\section{c. Model configuration}

The WRF-ARW version 3.6.1 initialized at 0000 UTC (1400 LST) for each day using the NCEP CFSv2 data are used to study the island-scale airflow and cloudiness under various trade wind conditions over Oahu. Three two-way nested domains are employed (Fig. 3), with horizontal grid sizes of 13.5, 4.5 , and $1.5 \mathrm{~km}$, respectively. The horizontal dimensions of the three domains are $65 \times 62,64 \times 58$, and $79 \times 64$, respectively. The simulations used in this study come from the $1.5-\mathrm{km}$ domain, which covers the entire island of Oahu. The mountaintops of the Koolau and the Waianae Ranges in the $1.5-\mathrm{km}$ domain are 740 and $887 \mathrm{~m}$, respectively. The model uses 38 vertical levels from the surface to 100-hPa with smaller increments (11 levels) at the lower levels and around the trade wind inversion layer than above (Chen and Feng 2001). A diffusive damping scheme is not used at the model top.

The physics options include the Betts-Miller-Janjić (BMJ) cumulus parameterization scheme (Janjić 1994, 2000), the Yonsei University (YSU) planetary boundary layer scheme (Hong et al. 2006), and the single-moment 6-class microphysics scheme (Hong and Lim 2006), which uses five prognostic hydrometeor categories (including cloud water, cloud ice, rain, snow, and graupel). The cloud droplet number concentration is reduced from the default value of 300 to $50 \mathrm{~cm}^{-3}$ because of the typically clean maritime air
TABLE 4. Error statistics of surface wind for model points corresponding to 17 Oahu weather stations during the 34 trade wind days from July to August 2013.

\begin{tabular}{lrrrrrrrr}
\hline \hline & \multicolumn{3}{c}{$U\left(\mathrm{~m} \mathrm{~s}^{-1}\right)$} & & \multicolumn{3}{c}{$V\left(\mathrm{~m} \mathrm{~s}^{-1}\right)$} \\
\cline { 2 - 4 } \cline { 7 - 8 } Station code & BIAS & MAE & RMSE & & BIAS & MAE & RMSE \\
\hline AN161 & -1.6 & 1.8 & 2.1 & & -0.6 & 1.0 & 1.3 \\
AN162 & -0.9 & 1.3 & 1.5 & & 0.5 & 0.8 & 1.1 \\
AN774 & 0.3 & 1.3 & 1.6 & & 0.6 & 0.8 & 1.1 \\
D3665 & -0.8 & 2.4 & 3.1 & & -0.1 & 1.5 & 1.9 \\
HFO04 & -0.8 & 1.0 & 1.3 & & 1.3 & 1.4 & 1.6 \\
HFO05 & -0.4 & 1.9 & 2.7 & & -0.1 & 0.8 & 1.2 \\
HFO06 & 0.9 & 1.4 & 1.8 & & 1.0 & 1.3 & 1.6 \\
HOFH & 0.0 & 1.1 & 1.5 & & -0.3 & 0.8 & 1.1 \\
KFWH & 0.4 & 1.0 & 1.3 & & 0.6 & 1.1 & 1.4 \\
KKRH & 0.6 & 2.0 & 2.5 & & 1.4 & 1.9 & 2.4 \\
KTAH & -0.2 & 0.9 & 1.3 & & -0.3 & 0.8 & 1.0 \\
OOUH & -1.0 & 1.3 & 1.6 & & -0.1 & 0.9 & 1.2 \\
PHJR & -0.8 & 1.1 & 1.4 & & -0.8 & 1.1 & 1.4 \\
PHNG & 0.2 & 0.8 & 1.1 & & 0.0 & 0.8 & 1.0 \\
PHNL & 1.3 & 1.7 & 2.2 & & 1.6 & 1.8 & 2.2 \\
SCBH & -0.5 & 1.1 & 1.4 & & 0.4 & 1.2 & 1.5 \\
WWFH & 0.6 & 1.2 & 1.6 & & 0.6 & 1.0 & 1.2 \\
\hline
\end{tabular}

found in Hawaii (Hudson 1993). The Rapid Radiative Transfer Model (Mlawer et al. 1997) longwave radiation scheme, Dudhia shortwave radiation scheme (Dudhia 1989), and revised surface layer scheme (Jiménez et al. 2012) are also used.

The Noah land surface model (Chen and Dudhia 2001) with four soil layers is employed using the soil properties compiled by Zhang et al. (2005a,b) from the soil surveys for the State of Hawaii (Foote et al. 1972; Sato et al. 1973). The U.S. Geological Survey (USGS) land use data compiled by Zhang et al. (2005a,b) are replaced by the more recent land cover from the Coastal Change Analysis Program (C-CAP, NOAA 2019) (https:// coast.noaa.gov/digitalcoast/data/ccapregional.html) (Hsiao et al. 2020). Since the diurnal heating cycle is dependent on the soil moisture, which affects the partitioning between the sensible and latent heat fluxes, the 24-h simulations of the high-resolution soil moisture and soil temperature from the model runs of the previous day are used as the updated soil conditions (Zhang et al. 2005a,b). After running the daily simulations for June 2013 with updated soil parameters for soil moisture and soil temperature every $24 \mathrm{~h}$, model runs for July and August 2013 are used for model verification. The first $12 \mathrm{~h}$ of model run are considered as the model spinup because the initial conditions interpolated from the CFSv2 analyses to the high-resolution model domains may not contain adequate information concerning local and orographic effects on airflow, clouds, and precipitation. Smolarkiewicz et al. (1988) showed that for the island of Hawaii, the model spinup time is about $3 \mathrm{~h}$. Thus, the $12-\mathrm{h}$ spinup window used is more than sufficient for the model to adjust to terrain. The $24-\mathrm{h}$ model data from the 13 th to the 36th hour for each day's run are used to study the simulated diurnal cycle (Van Nguyen et al. 2010; Li and Chen 2017; Hsiao et al. 2020; and others). 
(a)

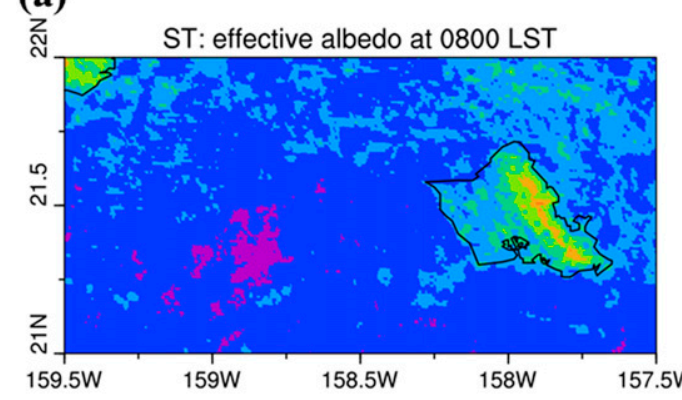

(c)

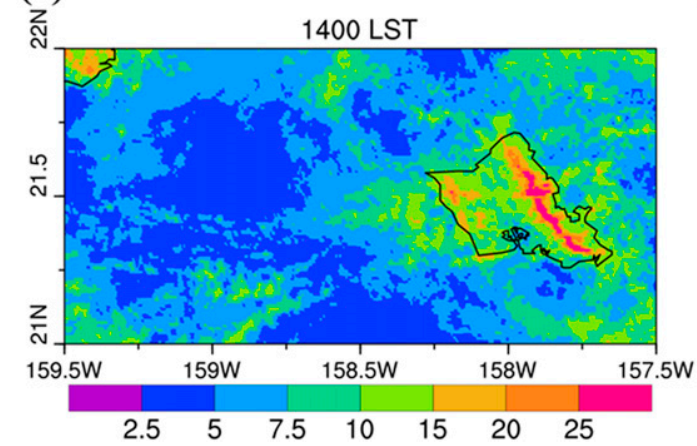

(b)

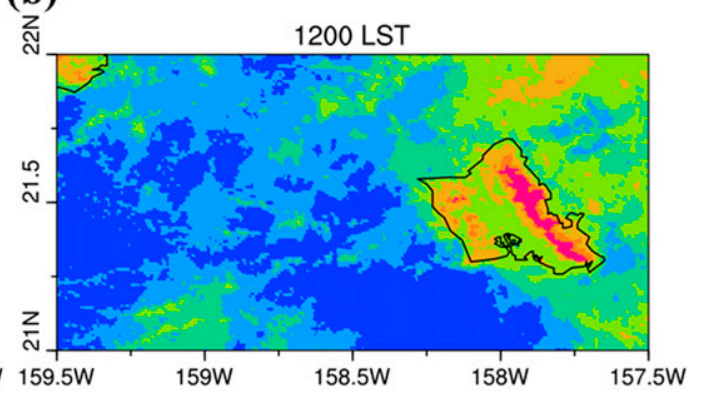

(d)

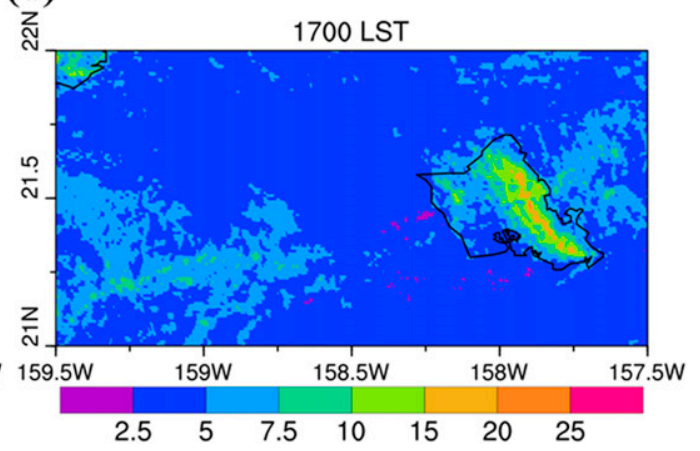

FIG. 5. Effective albedo (\%; color shading) derived from the GOES-15 visible channel over Oahu for strong trades at (a) 0800, (b) 1200, (c) 1400, and (d) 1700 LST during Jul-Aug 2013.

\section{d. Model verifications}

The simulated surface variables are interpolated to 24 surface stations every hour during the 34 trade wind cases. A four-point horizontal interpolation is used to calculate the simulated variables at the station locations. For interpolation of the surface air temperature in the coastal areas, only the nearest points over land are used. Then, the simulated surface air temperature is adjusted with an environmental lapse rate (a)

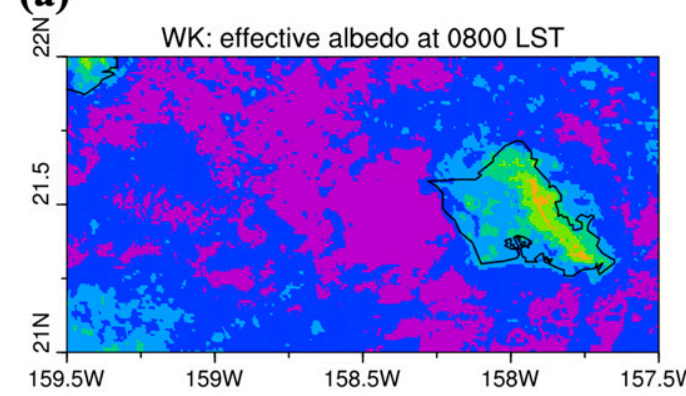

(c)

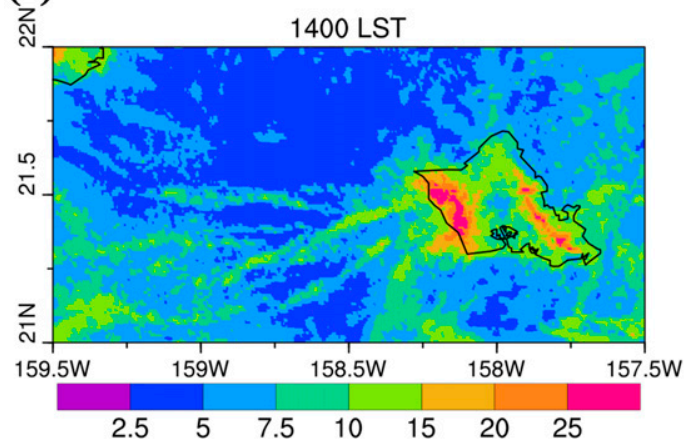

(b)

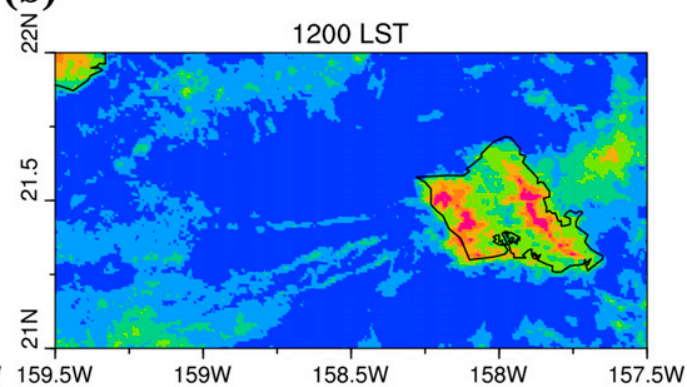

(d)

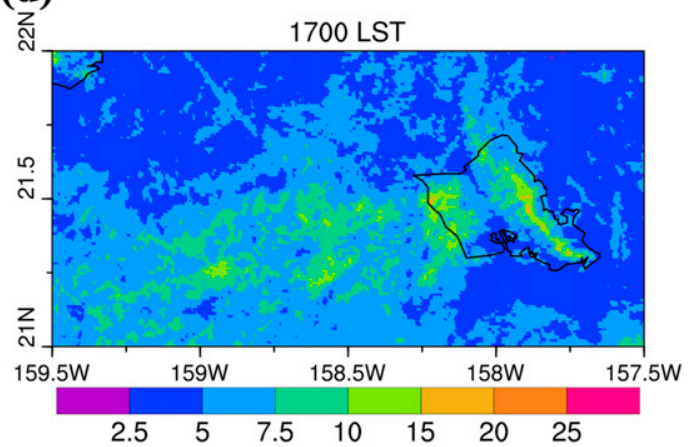

FIG. 6. As in Fig. 5, but for weak trades. 
(a)

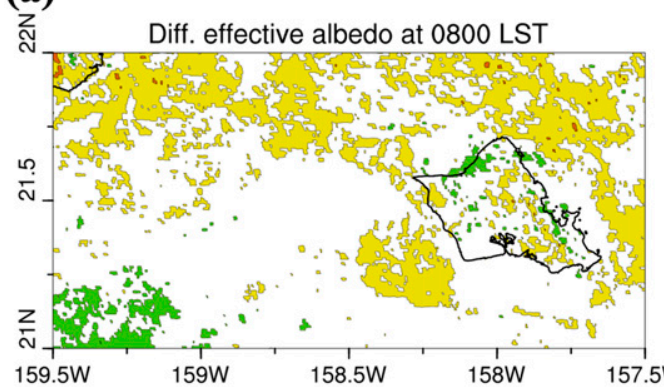

(c)

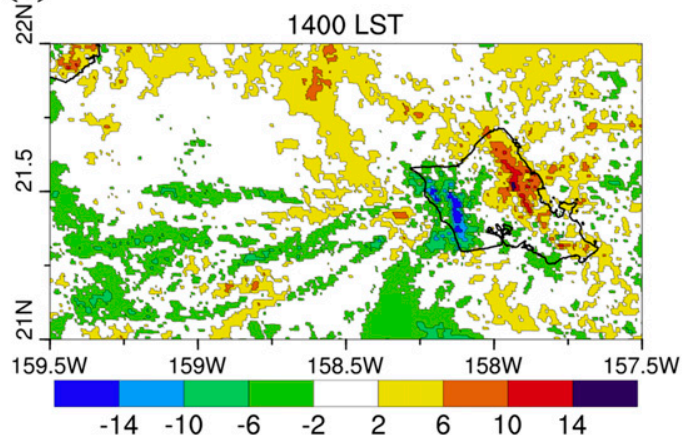

(b)

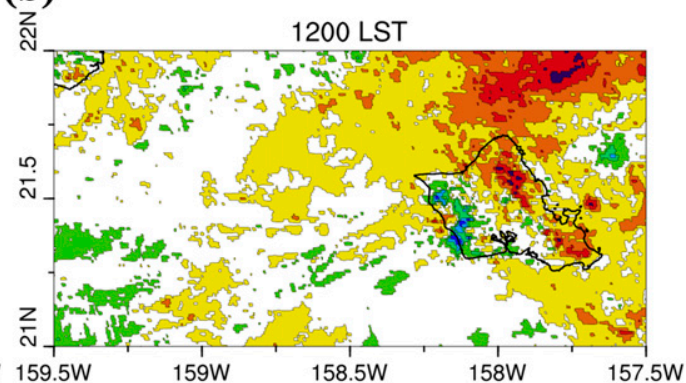

(d)

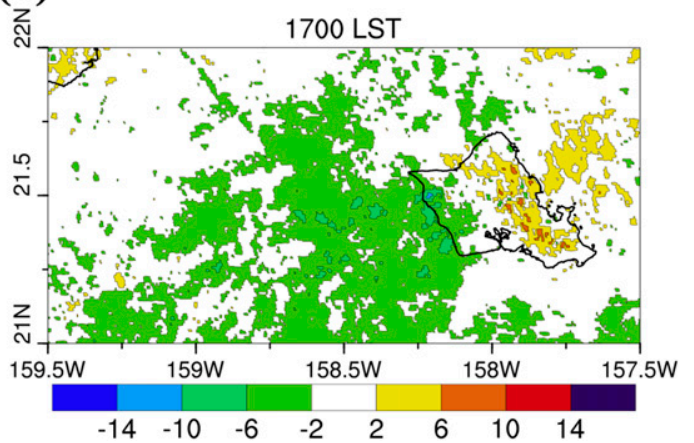

FIG. 7. The difference in effective albedo (\%) over Oahu between strong and weak trades (strong minus weak) at (a) 0800, (b) 1200, (c) 1400, and (d) 1700 LST during Jul-Aug 2013.

of $6.5 \mathrm{~K} \mathrm{~km}^{-1}$ to account for the height difference between the model terrain and the surface station elevation (Van Nguyen et al. 2010; Hsiao et al. 2020). The composite simulated surface winds at 0500, 0800, 1200, 1400, and
1700 LST during the 34 trade wind days are consistent with observations (Fig. 4). The simulated diurnal variations are consistent with observations (details are presented in the appendix). In addition to model bias, observational (a)

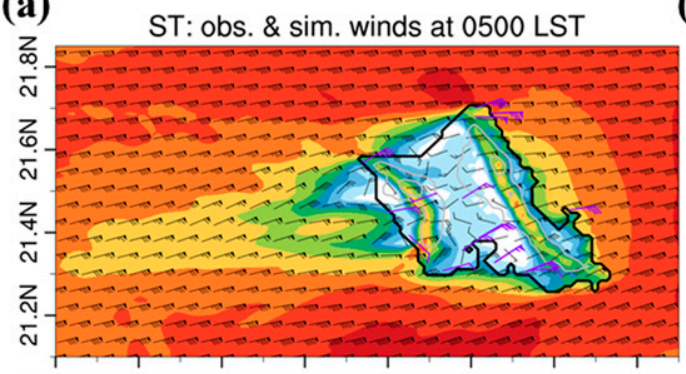

159.0W158.8W158.6W158.4W158.2W158.0W157.8W157.6W

(c)

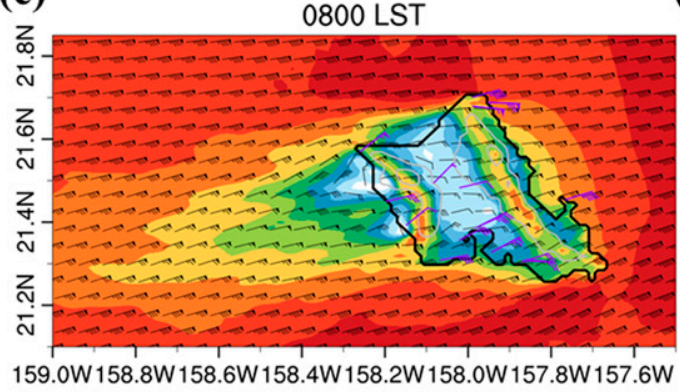

$\begin{array}{llllllllll}1 & 2 & 3 & 4 & 5 & 6 & 7 & 8 & 9 & 10\end{array}$ (b)

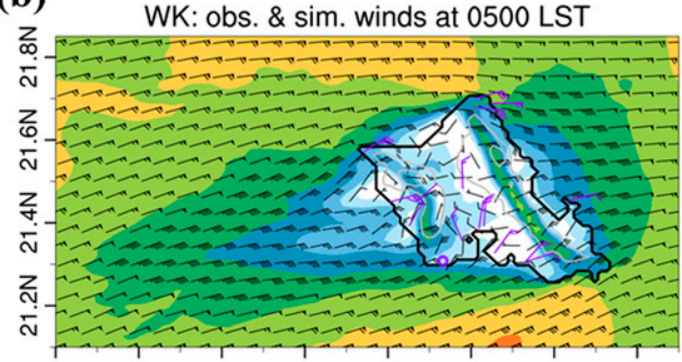

(d)

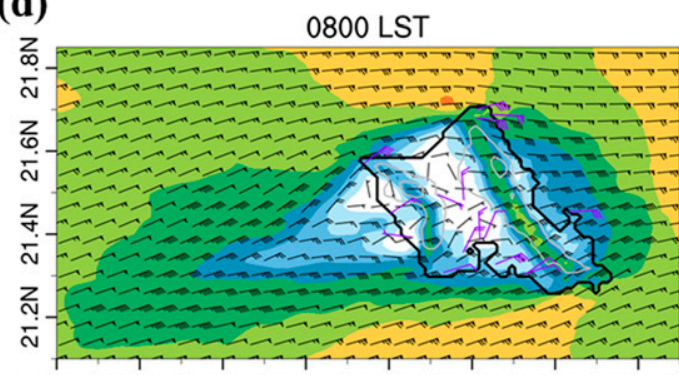

159.0W158.8W158.6W158.4W158.2W158.0W157.8W157.6W

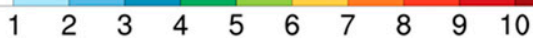

FIG. 8. As in Fig. 4, but for strong trades at (a) 0500 and (c) 0800 LST and for weak trades at (b) 0500 and (d) 0800 LST. 
(a)

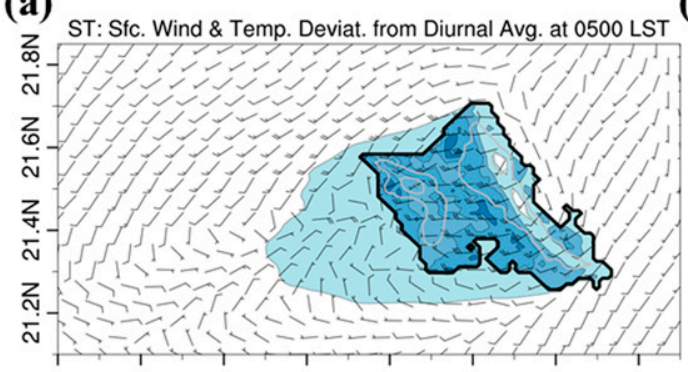

159.0W 158.8W 158.6W 158.4W 158.2W 158.0W 157.8W 157.6W

(c)

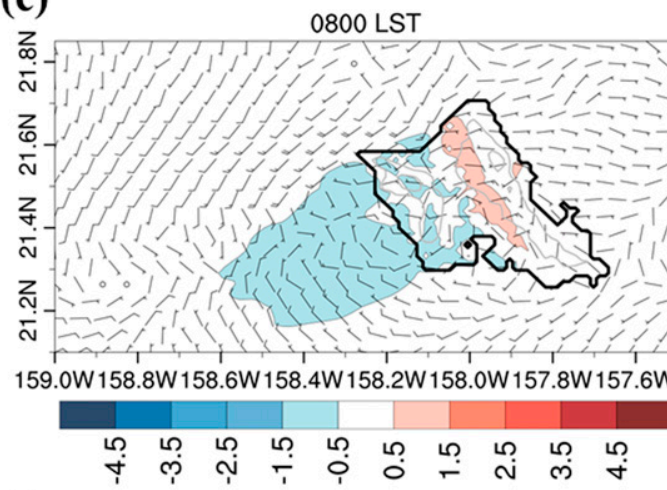

(e)

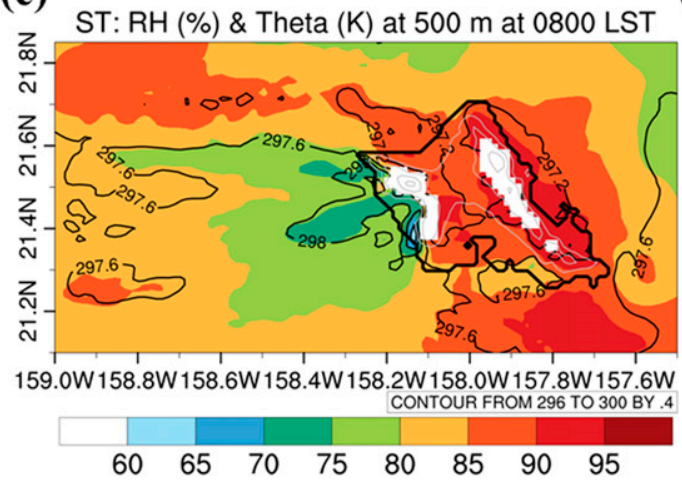

(b)

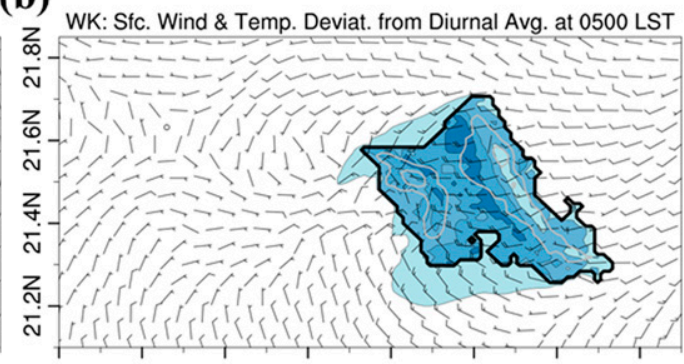

(d)

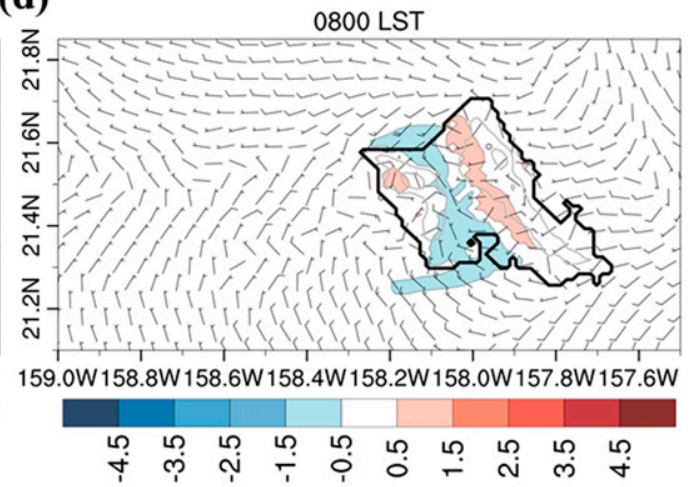

(f)

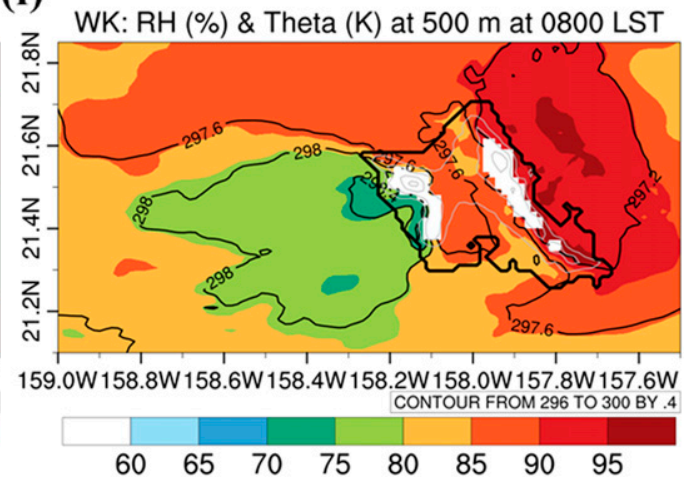

FIG. 9. Hourly deviations from the mean of surface wind (barbs) and temperature $\left({ }^{\circ} \mathrm{C}\right)$ for strong trades at (a) 0500 and (c) 0800 LST and for weak trades at (b) 0500 and (d) 0800 LST. Simulated RH (\%) and potential temperature (K) at 500-m height at 0800 LST for (e) strong trades and (f) weak trades.

uncertainties may also exist. Error statistics for simulated surface temperature, relative humidity $(\mathrm{RH})$, and surface winds are given in Tables 3 and 4 . The error statistics are comparable to those presented by Van Nguyen et al. (2010) using the fifth-generation Pennsylvania State UniversityNational Center for Atmospheric Research Mesoscale Model (MM5) model.

At KTAH and KFWH, the model underestimates surface temperature with a negative $1-1.5-\mathrm{K}$ bias (Table 3 ). The model systematically overestimates RH at 11 of the 13 stations (Table 3). Similarly, a larger RH positive bias $(>5 \%)$ is found over the windward side (KFWH and PHNG) and along the southern coast (PHJR, PHNL, and
WWFH). Three stations on the western coast (KKRH, HFO05, and D3665) have larger root-mean-square errors in zonal wind speed than other stations (Table 4). The zonal wind errors at these stations mainly occur during the daytime, even though simulated surface temperatures are comparable to observations (Table 3 ). In this case, the model errors may be partly due to the fact that the $1.5-\mathrm{km}$ grid size cannot accurately depict the steepness of the Waianae mountain range. Distances between AN161, AN162, and OOUH are less than $1.5 \mathrm{~km}$; however, surface winds at these stations (Fig. 4) are slightly different from each other, indicating that observational uncertainties may exist. 


\section{(a)}

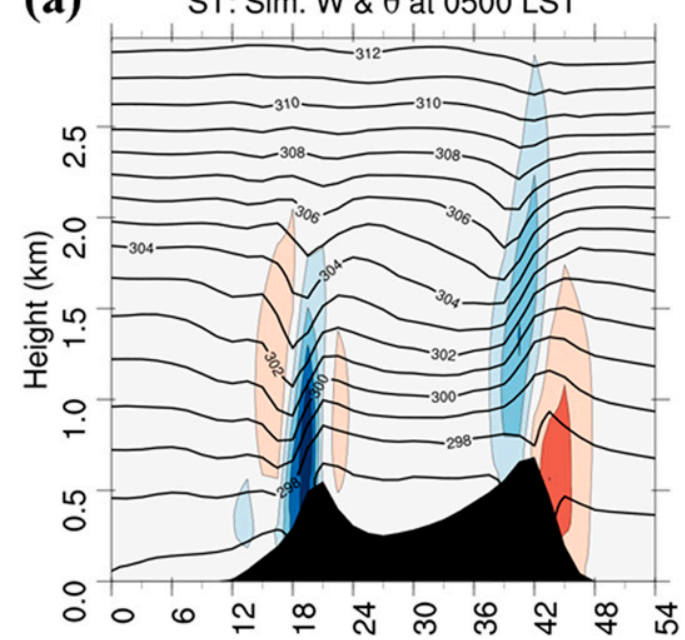

(c)

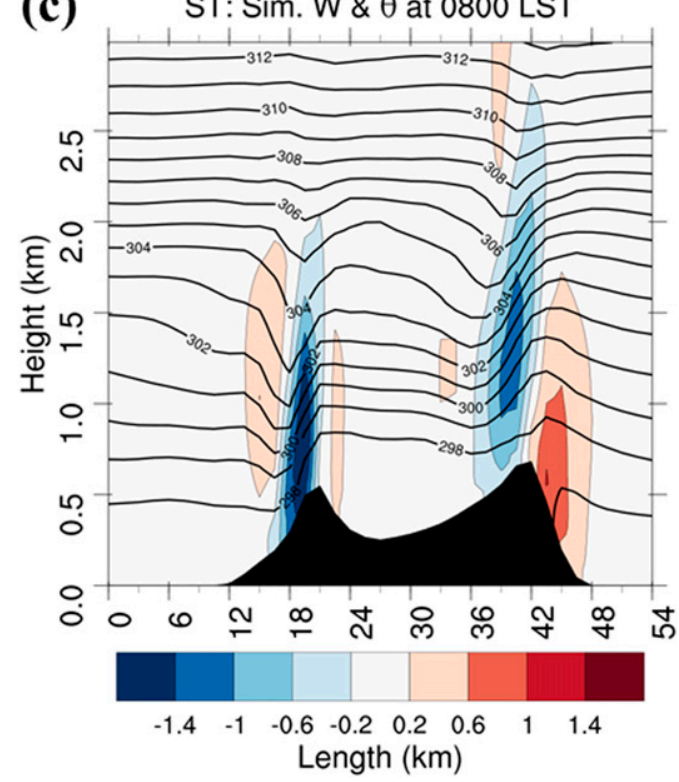

(b)

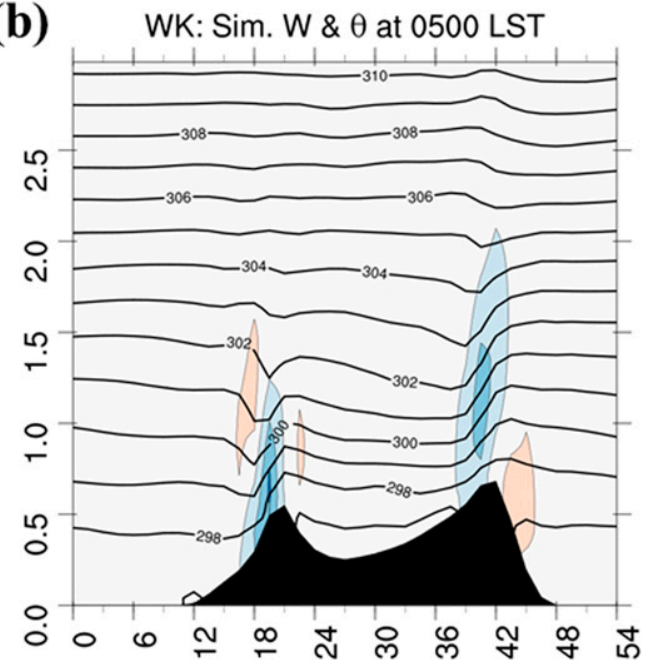

(d)

WK: Sim. W \& $\theta$ at 0800 LST

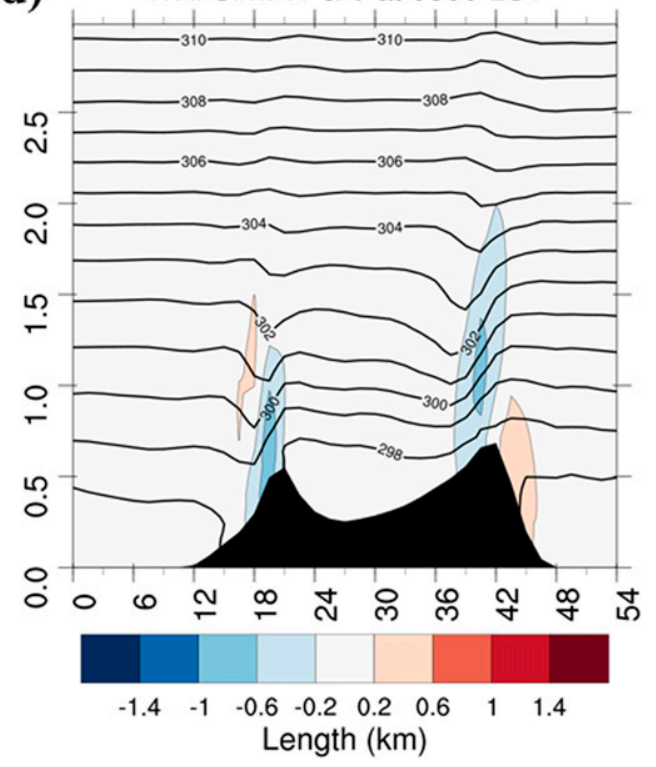

FIG. 10. The vertical cross section along the SW-NE line in Fig. 1 of simulated potential temperature (K; contours) and vertical motion ( $\mathrm{m} \mathrm{s}^{-1}$; color shading) for strong trades at (a) 0500 and (c) 0800 LST and for weak trades at (b) 0500 and (d) 0800 LST.

\section{Effects of trade wind strength on cloud patterns, airflow, and thermodynamic fields}

In this section, satellite observations and model simulations are used to investigate how trade wind speed affects the wake circulations and clouds off the leeside coast of Oahu. GOES-15 visible images are first converted to effective albedo to delineate differences in the distributions of clouds under strong and weak trade wind conditions during different times of the day. Then, the numerical simulations are used to study the influence of trade wind strength on circulations, thermal fields, and cloud distributions over the island and off the leeside coast during different times of day.

\section{a. Satellite observations of cloud patterns}

\section{1) STRONG TRADES}

There are large temporal variations in the effective albedo over and downstream of Oahu during the daytime (Fig. 5). In the early morning, the effective cloud albedo over the island increases after sunrise (Fig. 5a). The highest values $(>25 \%)$ occur over the Koolau Range at noon (Fig. 5b) due to direct sunlight and the development of orographic clouds caused by orographic blocking and lifting under combined strong trades and anabatic flow. These clouds extend to the island interior with a smaller secondary maximum $(\sim 15 \%-20 \%)$ over the peaks of the Waianae Range. The maximum effective albedo over the Koolau Range persists until early afternoon (Fig. 5c). 


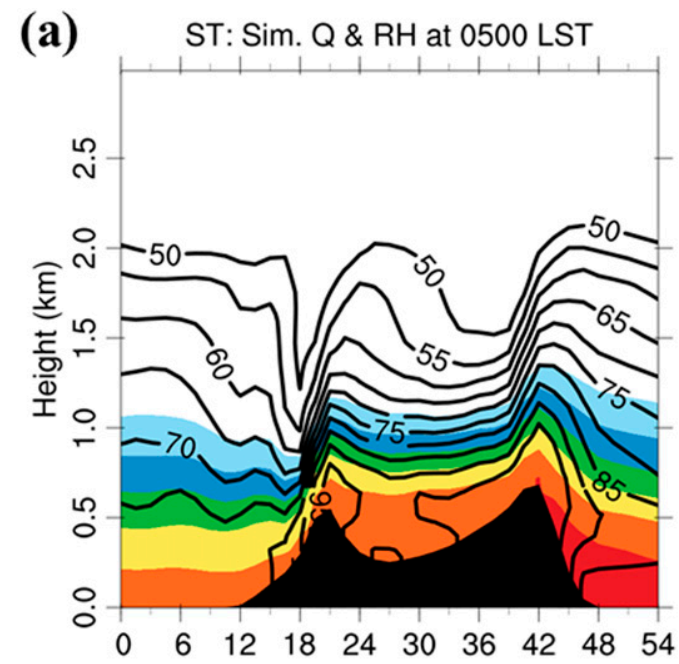

(c) ST: Sim. Q \& RH at 0800 LST

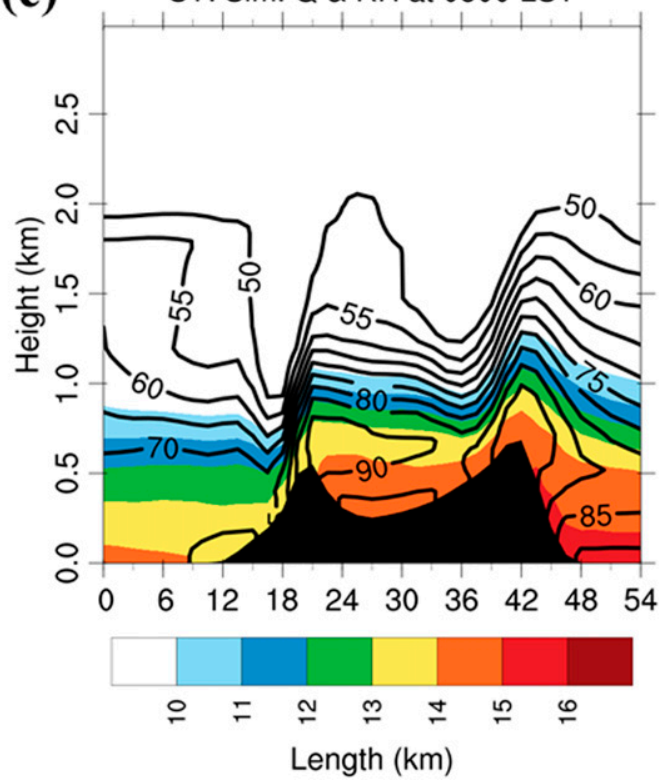

(b) WK: Sim. Q \& RH at 0500 LST

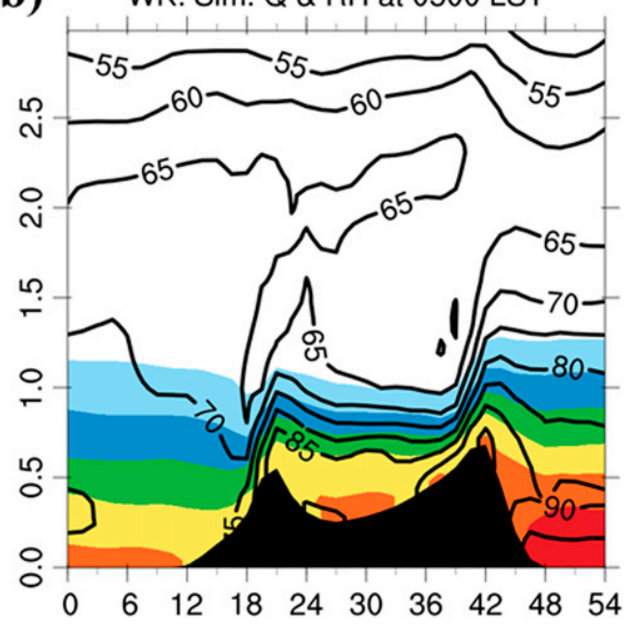

(d)

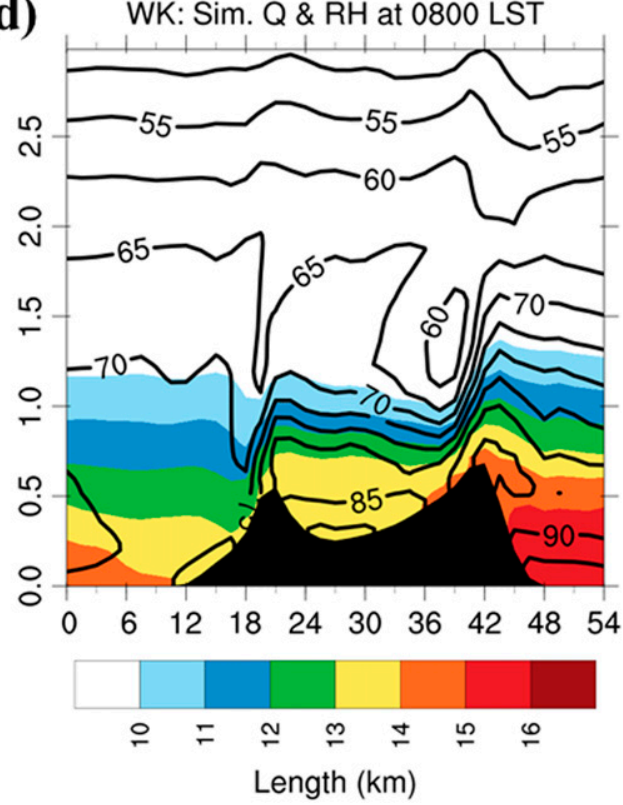

FIG. 11. As in Fig. 10, but for simulated vapor mixing ratio $\left(\mathrm{g} \mathrm{kg}^{-1}\right.$; color shading) and relative humidity (\%; contours).

Moisture removed from the incoming flow by orographic precipitation (Van Nguyen et al. 2010) results in lower effective albedo values over the Waianae Range $(\sim 15 \%)$ than over the Koolau Range during the same period under strong trades. The effective albedo associated with clouds downstream of the island is much lower $(<2.5 \%)$ as compared to the windward coast $(\sim 15 \%)$ in the early morning (Fig. 5a). In the early afternoon, the effective albedo over central Oahu increases to $>10 \%$, as compared to $20 \%$ over the windward coast (Fig. 5c). The effective albedo off the leeside coast decreases after the early afternoon and is low ( $<5 \%)$ by 1700 LST (Fig. 5d).

\section{2) WEAK TRADES}

The temporal and spatial variations of effective albedo are similar among strong trades and weak trades (Fig. 6).
With less orographic blocking and lifting, the effective albedo along the Koolau Range (Fig. 6), after sunrise and throughout the day, is less during weak trades (Fig. 7). The effective albedo over central Oahu is also less (Fig. 7). Over the Waianae Range and off the leeside coast, the effective albedo after sunrise is also less under weak trades (Figs. 6a and $7 \mathrm{a})$.

Under weak trades, with less moisture removal by orographic precipitation over the Koolau Range and the development of upslope flows on both sides of the Waianae Range (Hartley and Chen 2010), the values of effective cloud albedo over the Waianae Range (Figs. 6b and $7 \mathrm{~b})$ are larger $(\sim 25 \%)$ than during strong trades at $1200 \mathrm{LST}$. With continued solar heating, the effective cloud albedo over the Waianae Range continues to 

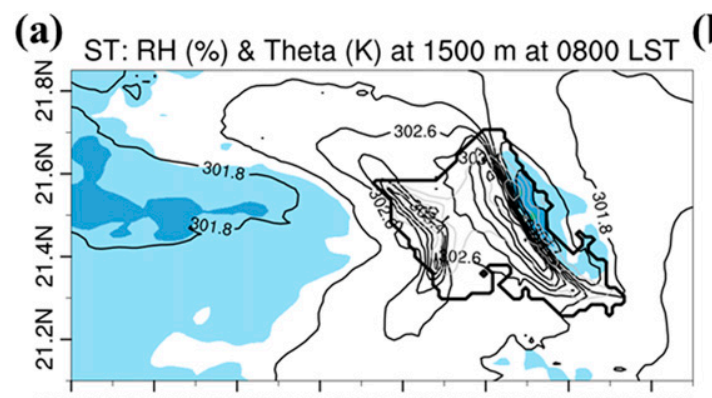

(b)

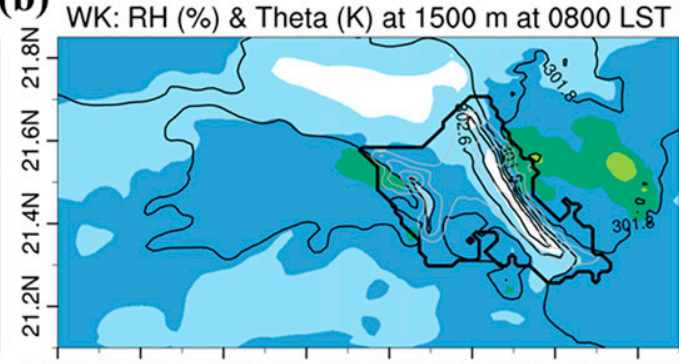
159.0W 158.8W 158.6W 158.4W 158.2W 158.0W157.8W 157.6W
CONTOUR FROM 301 TO 305 BY.4

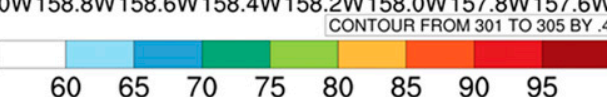

59.0W158.8W158.6W158.4W158.2W158.0W157.8W157.6W

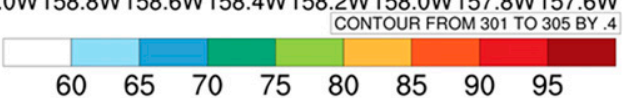

(c)

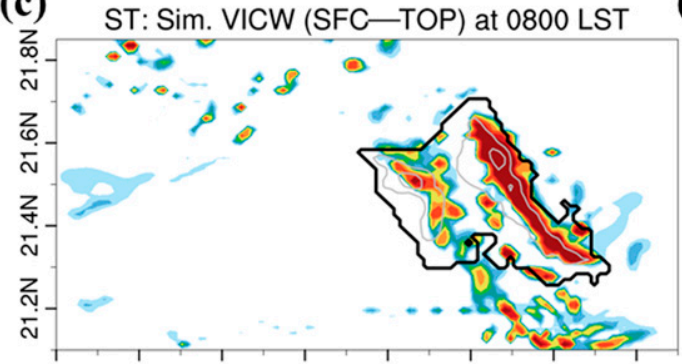

(d)

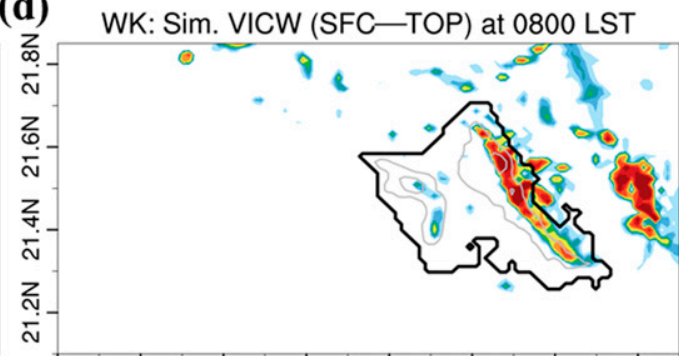

159.0W158.8W158.6W158.4W158.2W158.0W157.8W157.6W

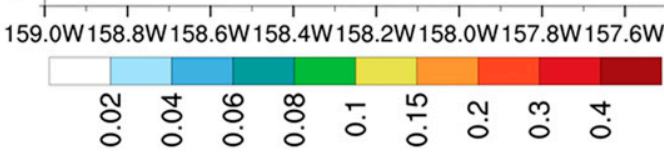

FIG. 12. Simulated RH (\%) and potential temperature (K) at 1500-m height at 0800 LST for (a) strong trades and (b) weak trades. Vertically integrated (from the surface to model top) cloud water (mm; shading) at 0800 LST for (c) strong trades and (d) weak trades.

increase and is greater and extends farther downstream of both Mount Kaala and Mount Palikea (Figs. 6c and 7c) in the early afternoon (Fig. 6c). Furthermore, the highest values of effective cloud albedo ( $>25 \%$ ) over the Waianae Range are more widespread than over the Koolau Range (Fig. 6c). The effective cloud albedo off the leeside coast for both trade wind conditions decreases in the late afternoon (Figs. 5d and 6d); however, the existence of these clouds off the leeside coast is more significant $(\sim 10 \%)$ and extensive in the late afternoon when trades are weaker (Fig. 7d).

In summary, after sunrise, the orographic clouds over the Koolau Range, due to a combination of orographic lifting and upslope flow, are more significant when trades are stronger. These clouds are advected westward over the island interior by the trade winds aloft. In response to continued solar heating over the island during the daytime, orographic clouds develop over the Waianae Range, and the western leeside coastal area; and are more significant under weak trades (Figs. 7b,c). In the late afternoon, the effective cloud albedo over the Waianae Range decreases. Nevertheless, the cloudiness extends farther off the western leeside coast (Fig. 6d) and is more extensive when trades are weaker (Fig. 7d). It appears that clouds in the wake zone of Oahu in the late afternoon hours are mainly the remnants of orographic clouds from the Waianae Range drifting downstream and are not generated along the axis of the leeside convergent zone as occurs off the leeside coast of the Big Island (Smith and Grubišic'1993; Yang and Chen 2003). This hypothesis will be further investigated in the next section using model results. The cause(s) of the more extensive cloud cover off the leeside coast in the late afternoon when trades are weaker (Fig. 7d) will also be investigated.

\section{b. Numerical simulations}

In this section, the diurnal cycle of island-scale airflow and cloudiness under strong and weak trade wind conditions is examined, especially the physical reasons for the variations in afternoon cloudiness off the leeside coast. Because the mountain and leeside cloud patterns are different between the morning and afternoon, we will first compare the model results in the early morning between strong and weak trades, followed by a comparison for the afternoon.

\section{1) EARLY MORNING}

At $0500 \mathrm{LST}$, for both strong and weak trade wind conditions, flow deceleration on the windward side, calm winds over the island interior, strong winds along the two 
(a)

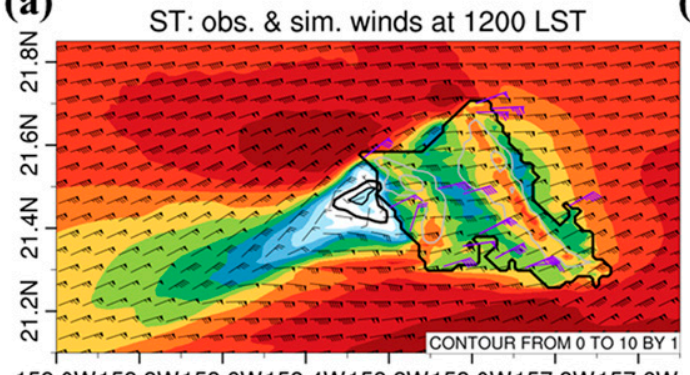

159.0W158.8W158.6W158.4W158.2W158.0W157.8W157.6W

(c)

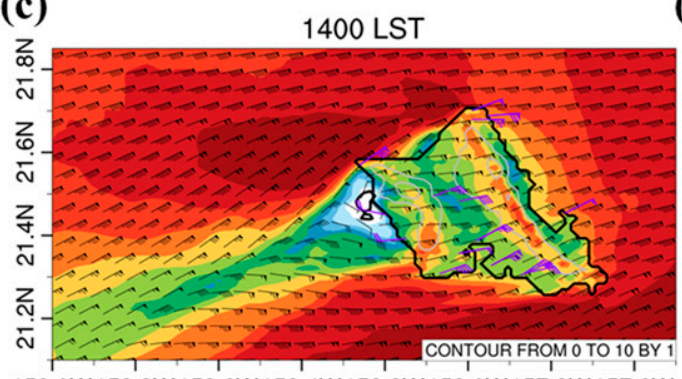

159.0W158.8W158.6W158.4W158.2W158.0W157.8W157.6W

(e)

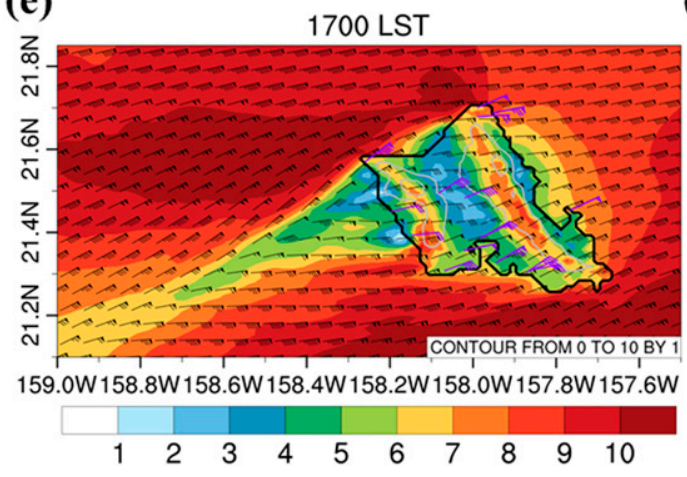

(b)

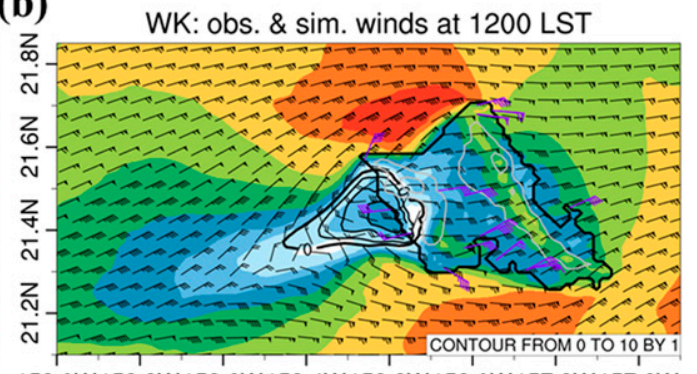

(d)

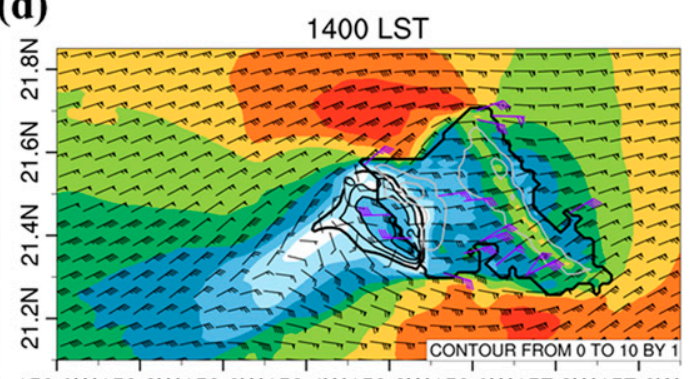

(f)

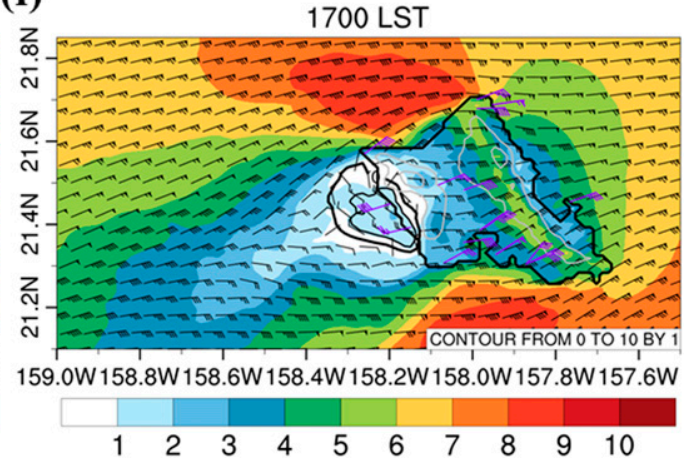

FIG. 13. As in Fig. 4, but for strong trades at (a) 1200, (c) 1400, and (e) 1700 LST. (b),(d),(f) As in (a), (c), and (e), but for weak trades. Black contours represent isotachs of $10-\mathrm{m}$ zonal wind speed.

mountain ranges, and katabatic winds on the eastern slopes of the Waianae Range are evident (Figs. 8a,b). Downslope/offshore flows $\left(<3 \mathrm{~m} \mathrm{~s}^{-1}\right)$ are present on the western leeside coast for both strong and weak trades, extending downstream with weaker winds in the wake zone (Fig. 8). Over the northern and the southern coasts, offshore flows are more evident when trades are weaker, consistent with observations (Fig. 8b). After sunrise, upstream flow deceleration becomes less significant with the upslope flow on the eastern slopes of the Waianae Range (Figs. 8c,d). Furthermore, the offshore flows along the southern and northern coast disappear (Figs. 8c,d).

Figure 9 displays surface temperature and wind deviations from the diurnal mean in the morning. At 0500 LST, the surface air over land is colder than the diurnal mean with a land-breeze/offshore flow component at the coast (Figs. 9a,b). The advection of cold air from the island interior to the wake zone is more significant when trades are stronger. After sunrise, it is warmer than the diurnal mean over parts of the central plain (Figs. 9c,d). In the meantime, the offshore wind component at the coast and mountain winds on the eastern slopes of the Waianae Range disappear. Under strong trades, the air over land, which is cooler than the diurnal mean, is advected off the western leeside coast (Fig. 9c).

At 0800 LST, at the 500-m height (Figs. 9e,f), along the Waianae coast and in the wake zone, the air is drier and warmer than upstream due to descending airflow in the lee. Nevertheless, in the wake zone, similar to the deviations from the mean at the surface in the morning (Figs. 9c,d), the air is slightly cooler and moister (Figs. 9e,f) when trades are stronger as the cooler (Figs. 10a,b) and moister (Figs. 11a,b) air over the island interior is advected off the leeside coast.

The vertical cross sections of simulated potential temperature and vertical motion along the southwest-northeast 
(a)

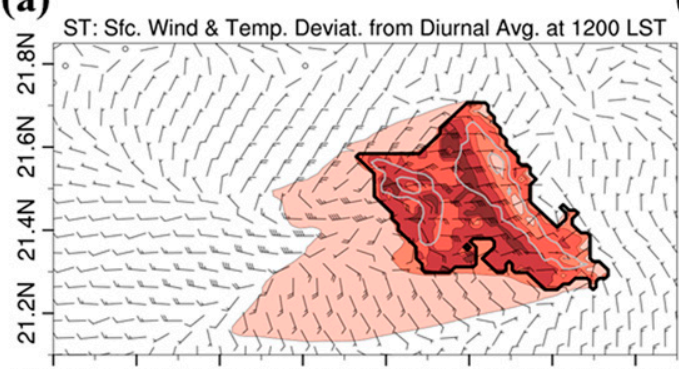

159.0W158.8W158.6W158.4W158.2W 158.0W 157.8W157.6W

(c)

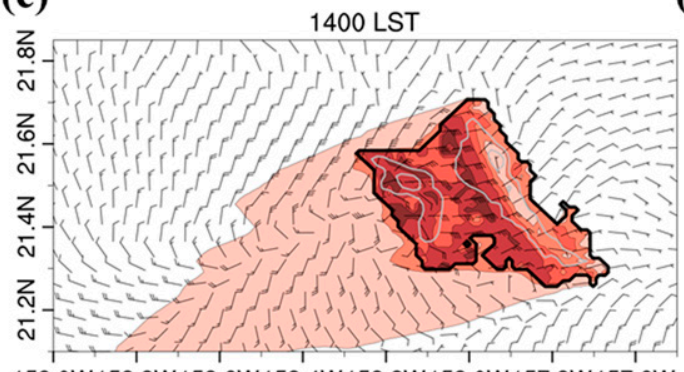

159.0W 158.8W158.6W158.4W $158.2 \mathrm{~W} 158.0 \mathrm{~W} 157.8 \mathrm{~W} 157.6 \mathrm{~W}$

(e)

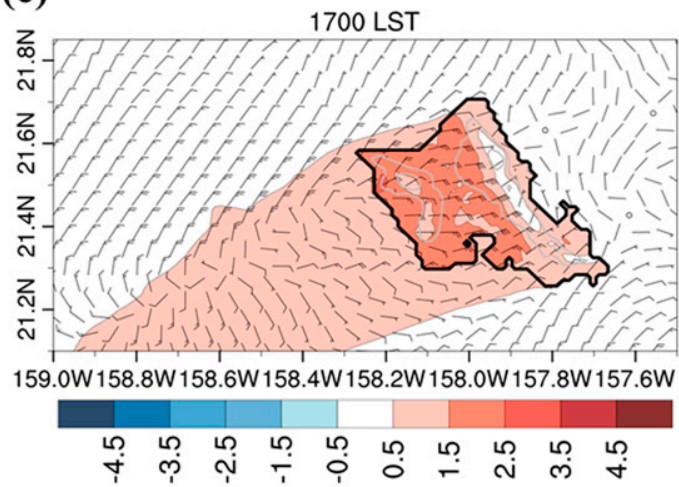

(b)

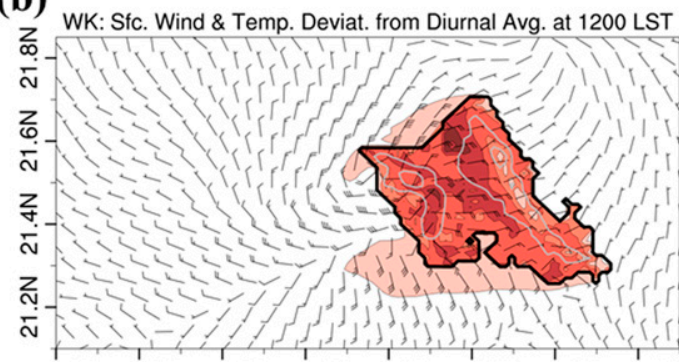

159.0W158.8W158.6W158.4W158.2W158.0W157.8W157.6W

(d)

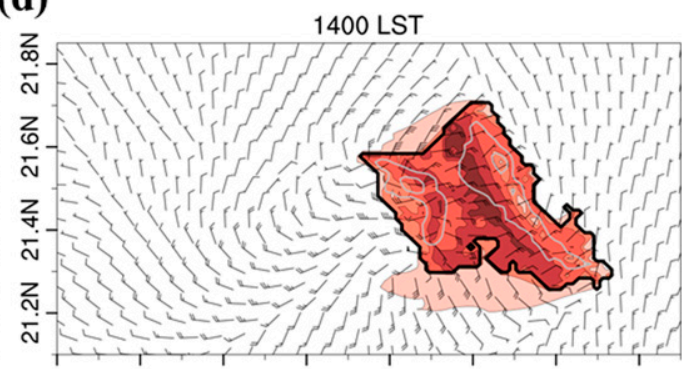

(f)

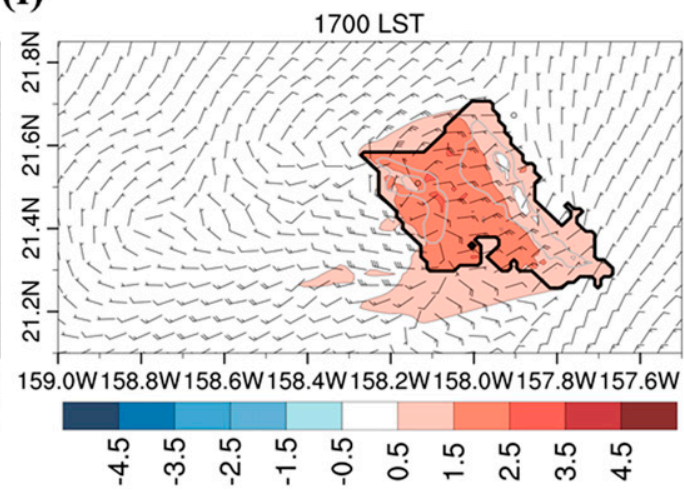

FIG. 14. Hourly deviations from the mean of surface wind (barbs) and temperature $\left({ }^{\circ} \mathrm{C}\right)$ for strong trades at (a) 1200 , (c) 1400, and (e) 1700 LST. (b),(d),(f) As in (a), (c), and (e), but for weak trades.

line in Fig. 1 (Fig. 10) show orographic lifting over the eastern slopes and descending airflow over the western slopes of the Koolau Range. Downslope winds are simulated above the leeside slopes of the Waianae Range, followed by a hydraulic jump (Fig. 10). The hydraulic jump is more significant under strong trade wind conditions. A weaker hydraulic jump is also present over the leeside slopes of the Koolau Range. Warming and drying are associated with downslope winds on the leeside slopes of both mountain ranges and are most significant before sunrise when trades are stronger (Figs. 10 and 11). Over the central plain, before sunrise, the air is relatively moist ( $\mathrm{RH}>90 \%$ and mixing ratio $>14 \mathrm{~g} \mathrm{~kg}^{-1}$ ) in low levels, especially under strong trades, as the incoming flow brings in maritime air from the windward side, over the island interior and into the wake zone (Figs. 11a,b). After sunrise, vertical mixing over the central Oahu plain is greater under weak winds, with relatively dry air in low levels (Figs. 11c,d).

At the 1500-m level, the impact of the mountain waves aloft is evident (Figs. 12a,b). For strong trades, significant warming and drying above the leeside slopes of both mountain ranges is apparent (Fig. 12a). Downstream of the northern and southwestern coasts, warming and drying associated with tip jets found off the northern and southern corners of the island (Reeve and Kolstad 2011; Hitzl et al. 2014) is more significant when trades are stronger. In the wake zone, the air is slightly moister $(\mathrm{RH}>65 \%)$ and cooler when trades are weaker (Figs. 12a,b).

In the morning, more cloud liquid water is simulated over the Koolau Range, central Oahu, and the eastern slopes of the Waianae Range (Figs. 12c,d), as stronger impinging trades are lifted by the mountains. Furthermore, westward advection of the cloud water content from the Koolau Range toward the 
(a)

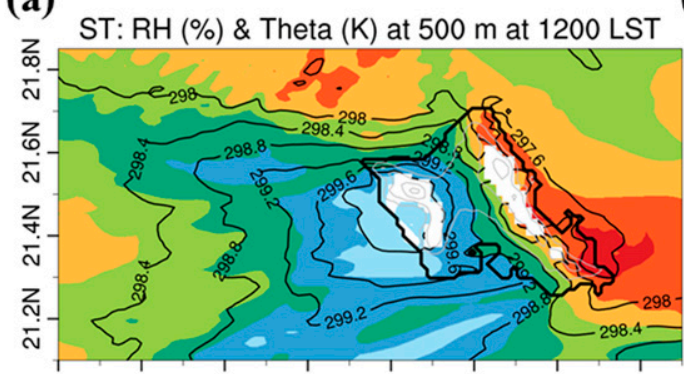

(c)

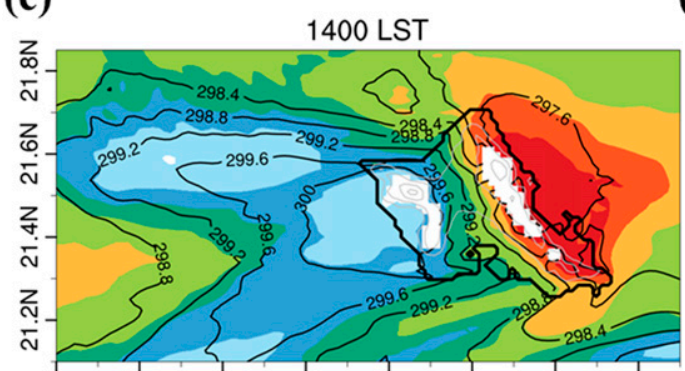

159.0W158.8W158.6W158.4W158.2W158.0W157.8W157.6W

(e)

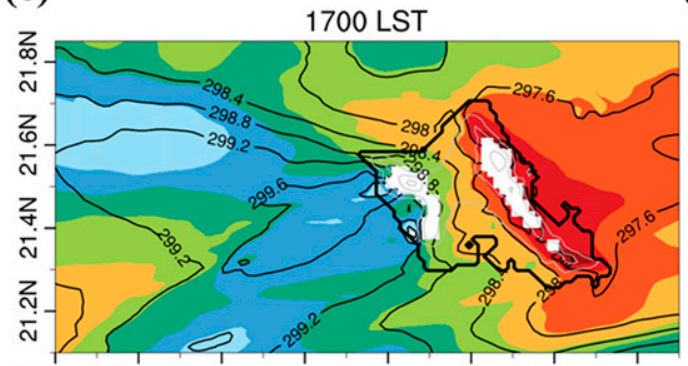

159.0W158.8W158.6W158.4W158.2W158.0W157.8W157.6W

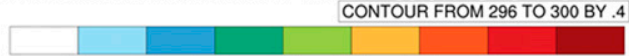

$\begin{array}{llllllll}60 & 65 & 70 & 75 & 80 & 85 & 90 & 95\end{array}$ (b)

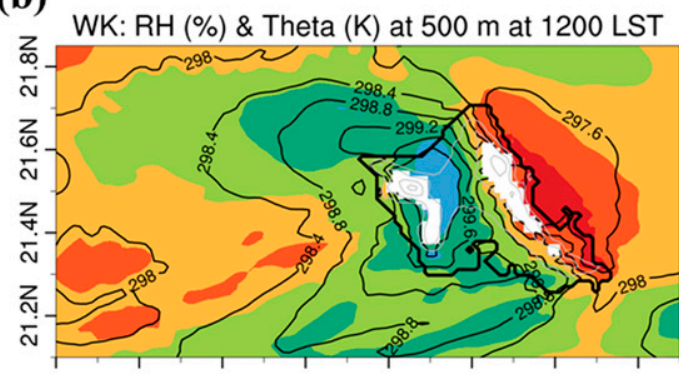

159.0W158.8W158.6W158.4W 158.2W 158.0W157.8W157.6W

(d)

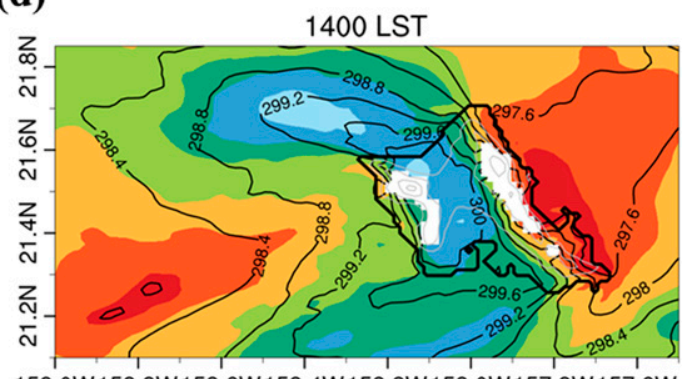

(f)

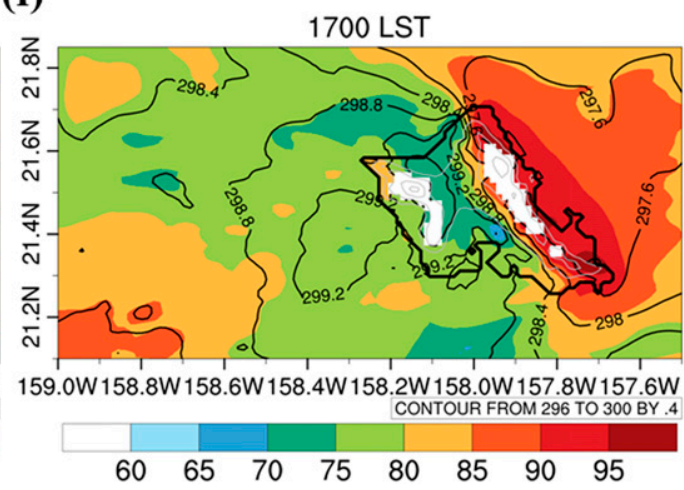

FIG. 15. Simulated RH (\%) and potential temperature (K) at 500-m height for strong trades at (a) 1200, (c) 1400, and (e) 1700 LST and for weak trades at (b) 1200, (d) 1400, and (f) 1700 LST.

island interior by the trade winds aloft is more significant when trades are stronger, consistent with satellite observations (Figs. 5 and 6). The vertically integrated cloud water over the Waianae Range is significantly less than over the Koolau Range due to rain shadow effects (Figs. 12c,d), especially under weak trades.

\section{2) Afternoon}

In this section, we examine the occurrence of cloudiness over the wake zone in the afternoon. The differences in the evolution of airflow, temperature, moisture, and offshore clouds between strong and weak trades are investigated using model results.

In the afternoon, flow deceleration along the windward side is less significant than at night with combined anabatic/trade wind flow over the eastern slopes of the Koolau Range (Fig. 13). The tip jets $\left(>10 \mathrm{~m} \mathrm{~s}^{-1}\right)$ around the northern and southern corners of the island are stronger and closer to the coast in the afternoon hours than in the early morning. Under weak trades, onshore flow is simulated from 1200 to 1700 LST along the leeside coast, consistent with observations from two surface stations (HFO05 and D3665) (Figs. 13b,d,f). Conversely, the westerly onshore flow along the western coast is only simulated at 1200 and 1400 LST during strong trades, with much smaller horizontal extent (Figs. 13a,c,e). In both cases, the orientation of the wake zone is aligned approximately with the upstream flow direction; however, the wake is narrower and extends farther downstream during strong trades than weak trades (Figs. 13a,c,e). The sea-breeze circulations along the western leeside coast are similar to those observed over the northwestern coast of the island of Hawaii, in the lee of the Waimea Saddle, where the ridge line is below the trade wind inversion (Schroeder 1981; Zhang et al. 2005c). 
(a)

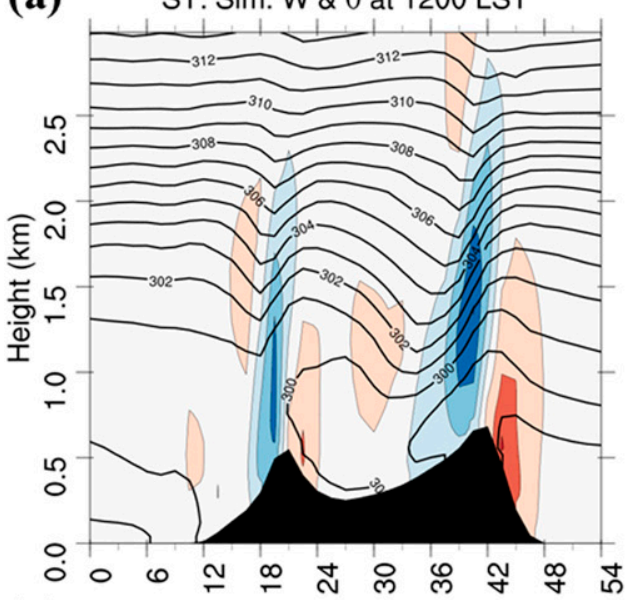

(c)

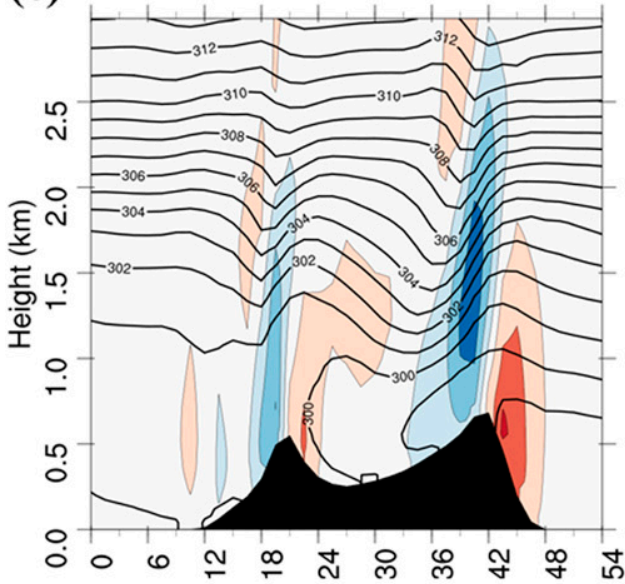

(e)

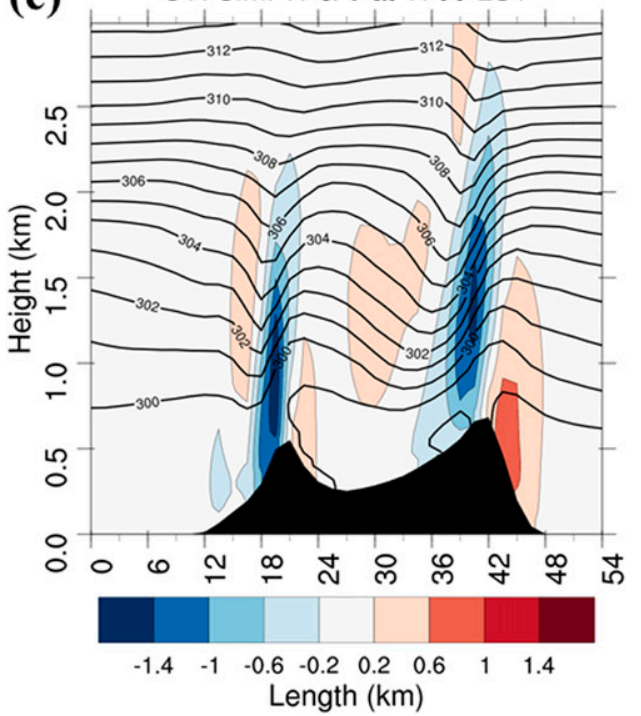

(b) WK: Sim. W \& $\theta$ at 1200 LST

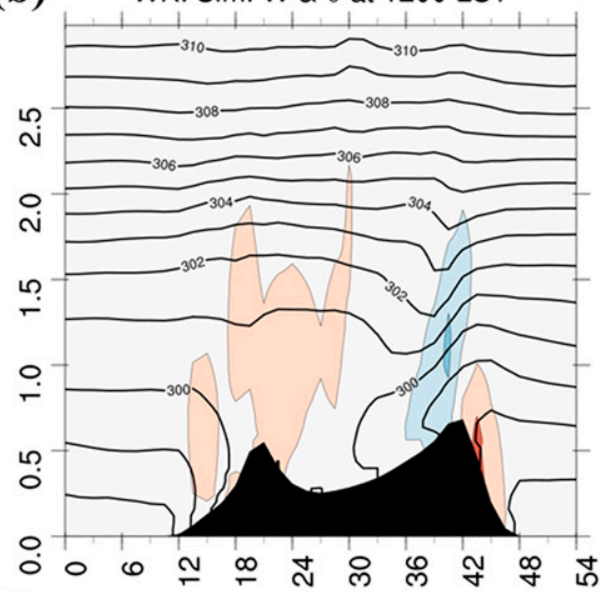

(d)

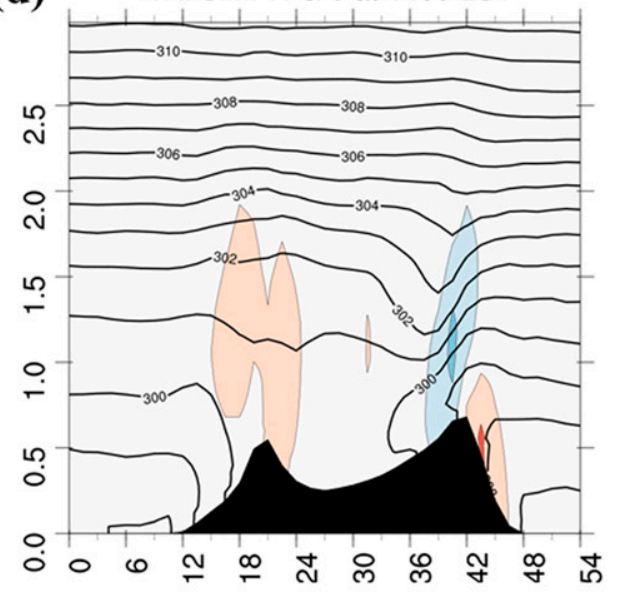

(f) WK: Sim. W \& $\theta$ at 1700 LST

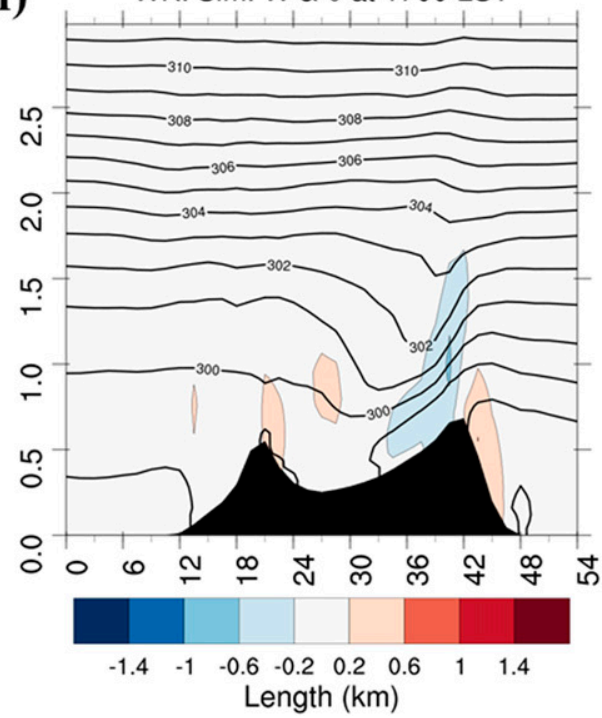

FIG. 16. As in Fig. 10, but at (a),(b) 1200, (c),(d) 1400, and (e),(f) 1700 LST. 
(a) ST: Sim. Q \& RH at 1200 LST

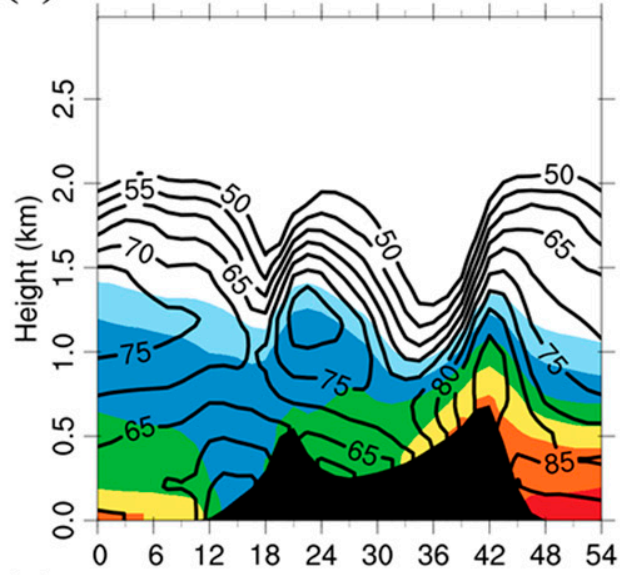

(c)

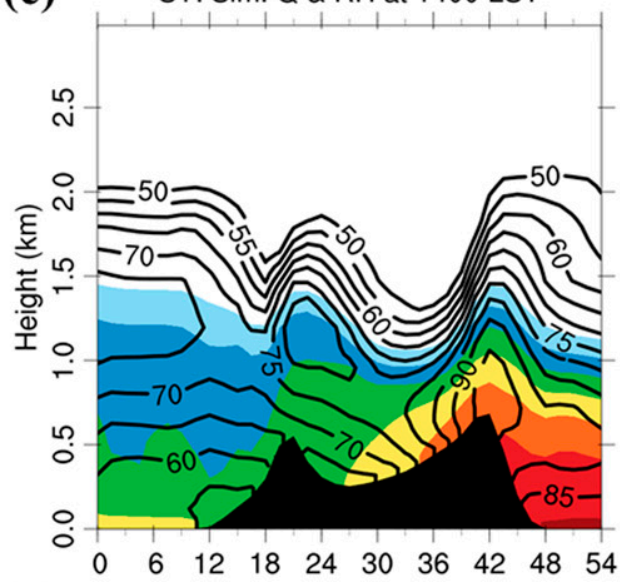

(e)

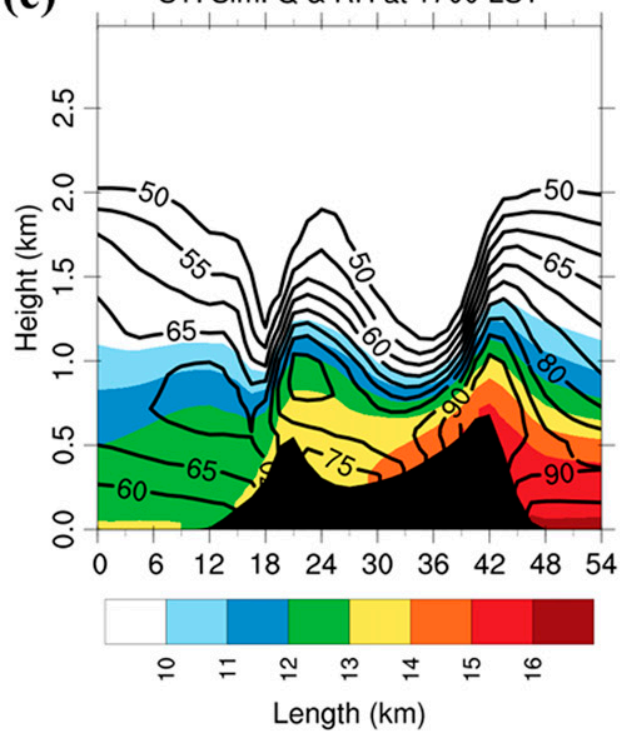

(b) WK: Sim. Q \& RH at 1200 LST

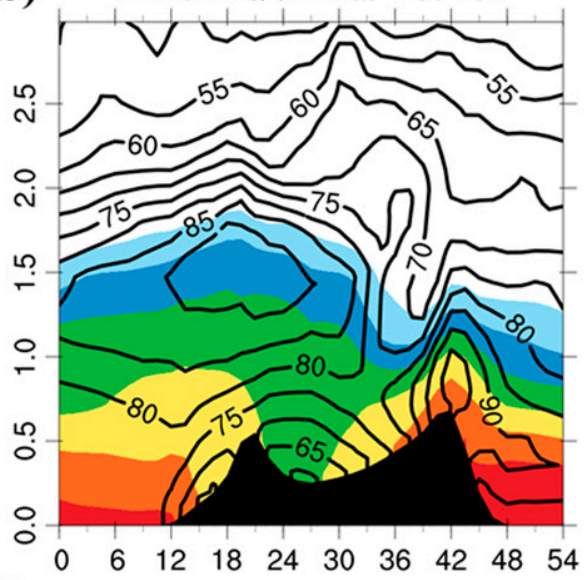

(d)

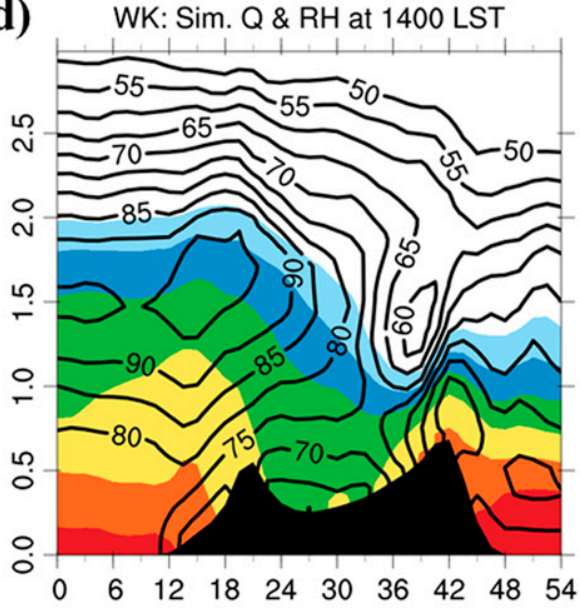

(f)

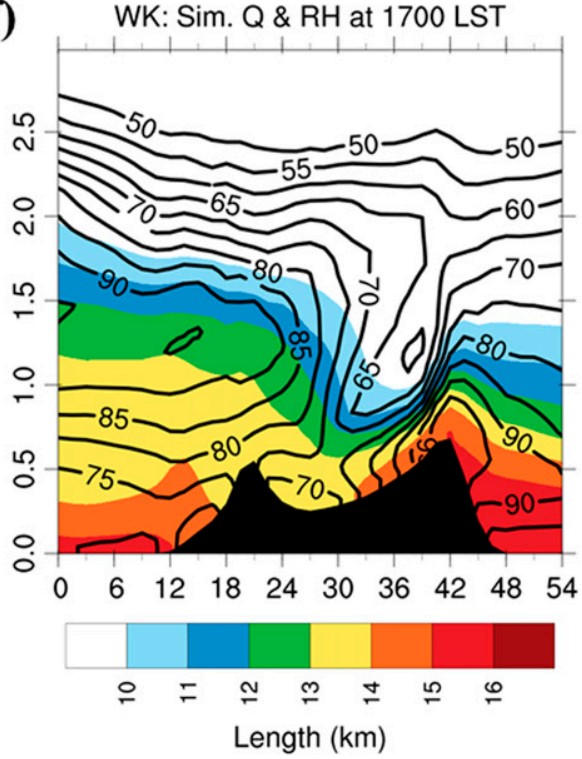

FIG. 17. As in Fig. 16, but for simulated vapor mixing ratio ( $\mathrm{g} \mathrm{kg}^{-1}$; color shading) and relative humidity (\%; contours). 
(a) ST: Sim. Qcloud \& Wind at 1200 LST

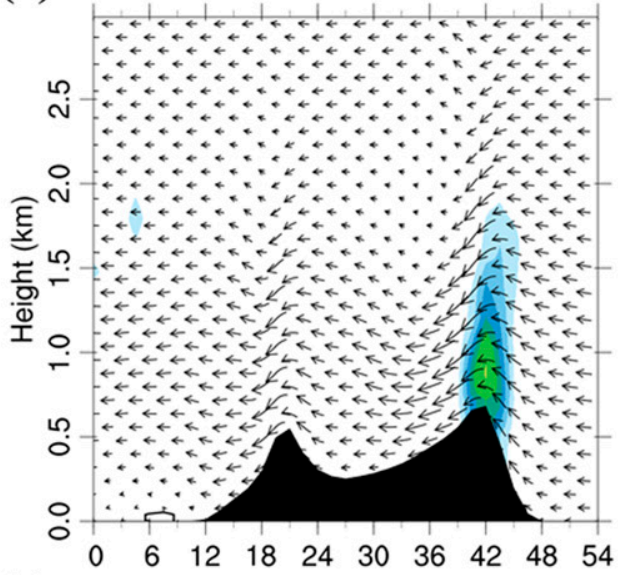

(c) ST: Sim. Qcloud \& Wind at 1400 LST

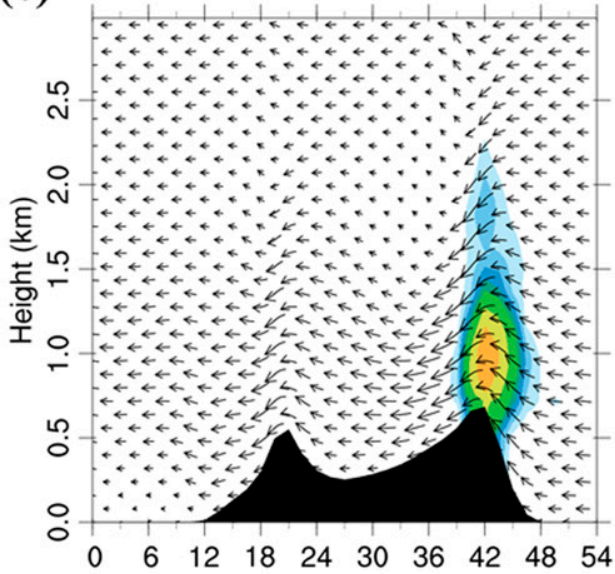

(e) ST: Sim. Qcloud \& Wind at 1700 LST

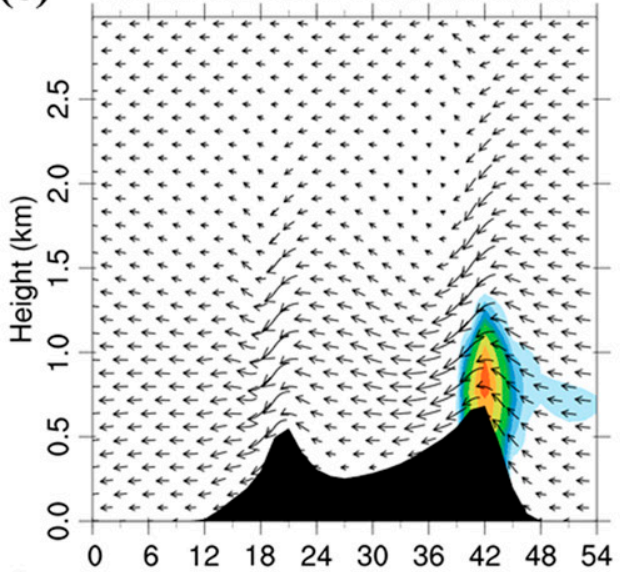

2

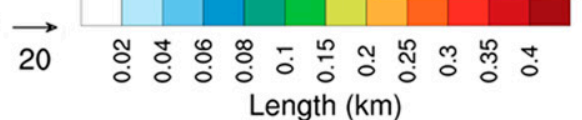

(b) WK: Sim. Qcloud \& Wind at 1200 LST

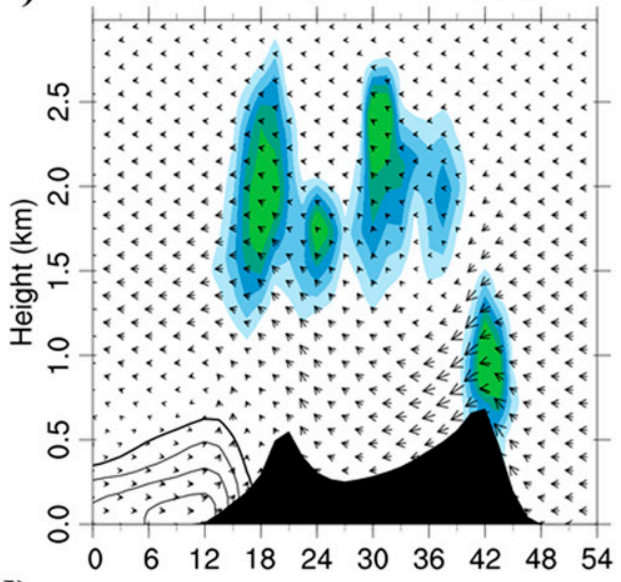

(d) WK: Sim. Qcloud \& Wind at 1400 LST

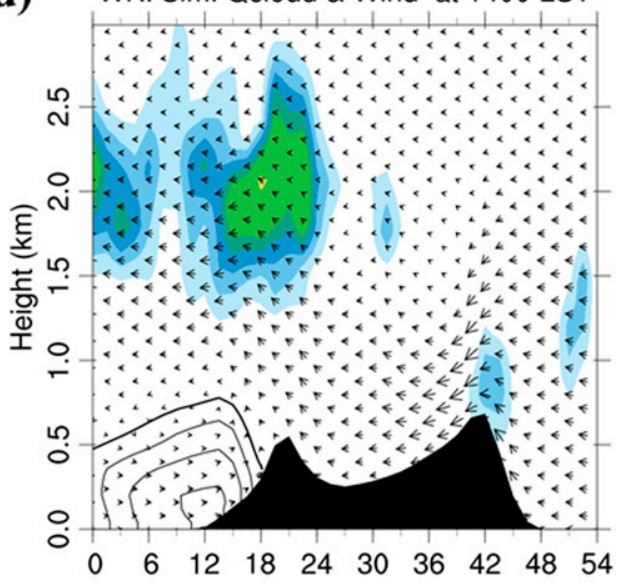

(f)

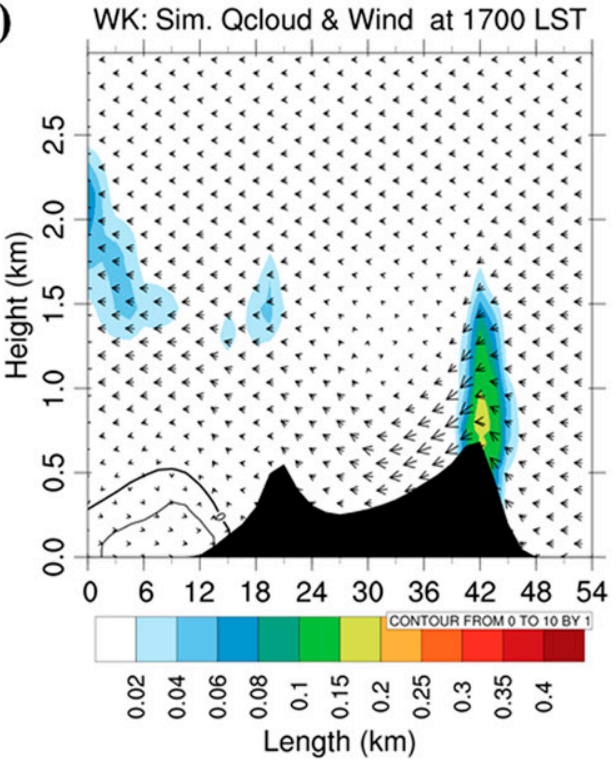

FIG. 18. As in Fig. 16, but for simulated cloud water mixing ratio $\left(\mathrm{g} \mathrm{kg}^{-1}\right.$; color shading) and horizontal wind (projected along the SW-NE line) and vertical wind $\left(u: \mathrm{m} \mathrm{s}^{-1} ; w: 10 \mathrm{~cm} \mathrm{~s}^{-1}\right.$; arrows). Black contours represent isotachs of $10-\mathrm{m}$ zonal wind speed. 
(a)

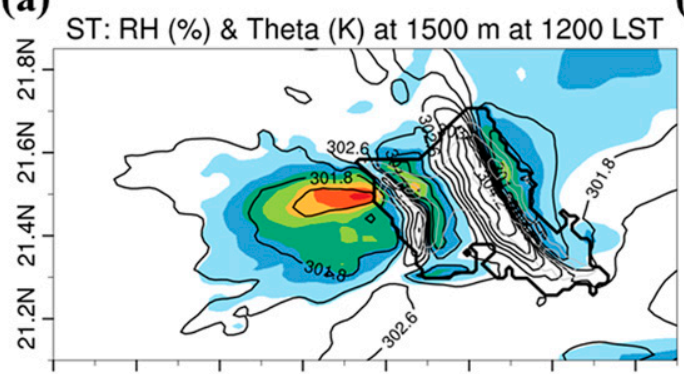

(c)

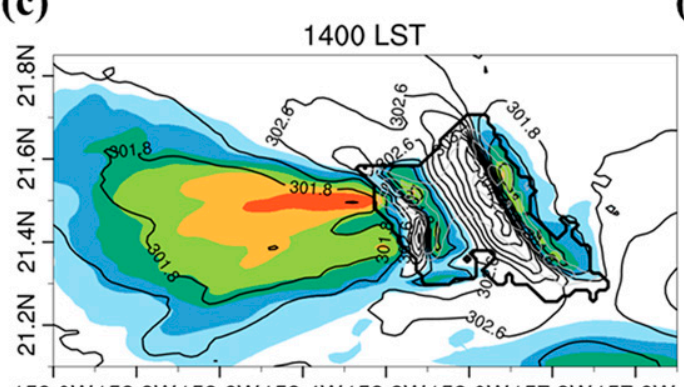

(e)

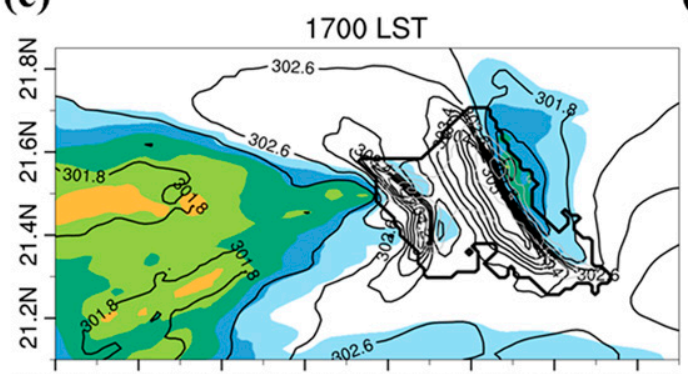

159.0W158.8W158.6W158.4W158.2W158.0W157.8W157.6W

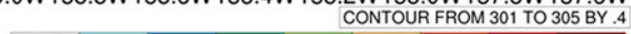

$\begin{array}{llllllll}60 & 65 & 70 & 75 & 80 & 85 & 90 & 95\end{array}$ (b)

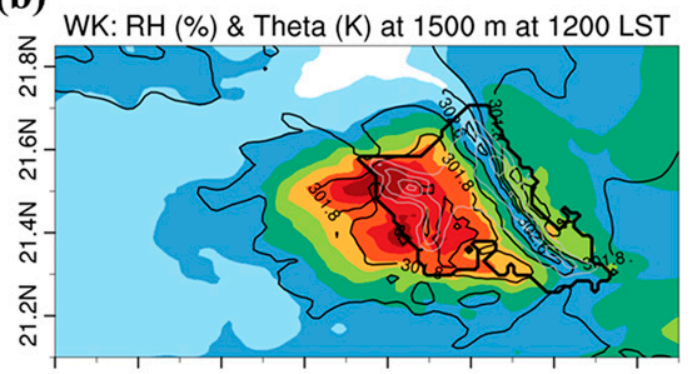

159.0W158.8W158.6W 158.4W 158.2W 158.0W157.8W157.6W

(d)

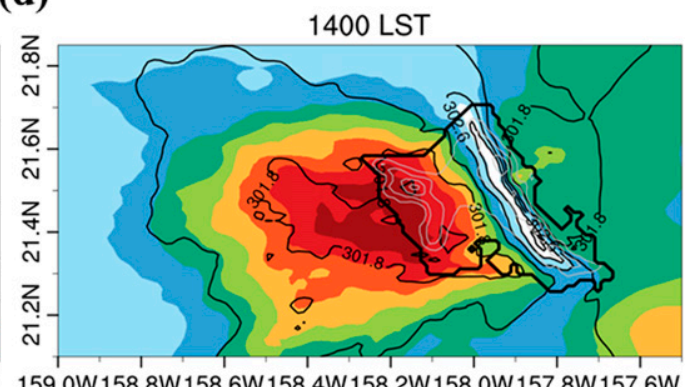

(f)

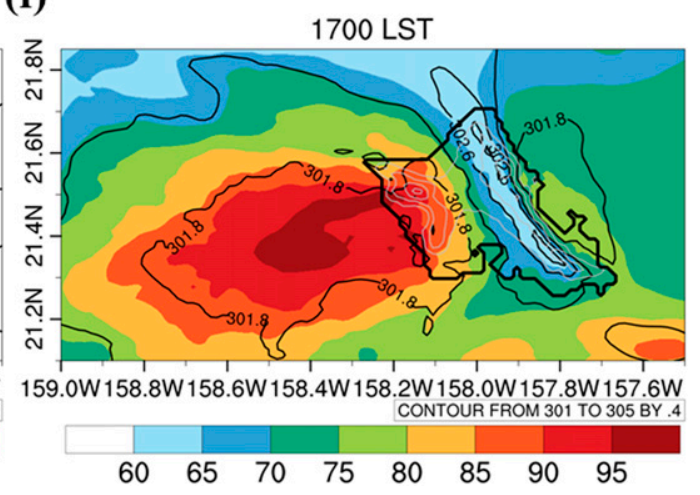

FIG. 19. As in Fig. 15, but at 1500-m height.

Figure 14 shows that appreciable land surface heating and adiabatic warming over the leeside slopes of Koolau Range are simulated in the afternoon under both strong and weak trades. For strong trades (Figs. 14a,c,e), the adiabatic warming over the western leeside slopes of both mountain ranges due to downslope winds is greater than during weak trades, with a maximum $>4.5^{\circ} \mathrm{C}$. The westerly wind component along the axis of the wake zone and the regions that are warmer than the diurnal mean $\left(\sim 1.5^{\circ} \mathrm{C}\right)$ offshore under strong trades attest to the warm advection by the mean flow in the afternoon hours, as suggested by Yang et al. (2008b,c). However, the convergence that is induced in the wake zone (Figs. 14a,c) is apparently inadequate to initiate deep convection due to significant warming and drying off the western leeside coast and a relatively high LCL $(\sim 1200 \mathrm{~m})$ (Figs. 15a,c,e). For weak trades, the regions that are warmer than the diurnal mean in the afternoon are mainly simulated over the island, with the westerly reversed flow in the wake zone (Figs. 14b,d,f). Thus, under weak trades, the warming over leeside waters is less significant $(<299.5 \mathrm{~K})$ and conditions remain relatively moist $(\mathrm{RH}>$ $75 \%$ ) (Figs. 15b,d,f).

Along the SW-NE line in Fig. 1, it is apparent that at 1200 LST, for weak trades, vertical mixing is more significant over the central plain than during strong trades, with uniform potential temperature $(>300 \mathrm{~K})$ at low levels (Figs. 16a,b). The hydraulic jump over the Waianae Range is weaker than during the early morning hours for strong trades and is completely absent during weak trades. Furthermore, under weak trades, rising motions due to orographic lifting by combined upslope-trade wind flow occurs over the windward side of the Waianae Range while upslope flow and rising motion occur over the western leeside slopes (Fig. 16b), with $\mathrm{RH}>80 \%$ above the ridge tops and a maximum $\mathrm{RH}>90 \%$ at the $1.5-\mathrm{km}$ height level (Fig. 17b). The rising motions over the windward side of the 
(a) ST: Sim. VICW (SFC-TOP) at 1200 LST

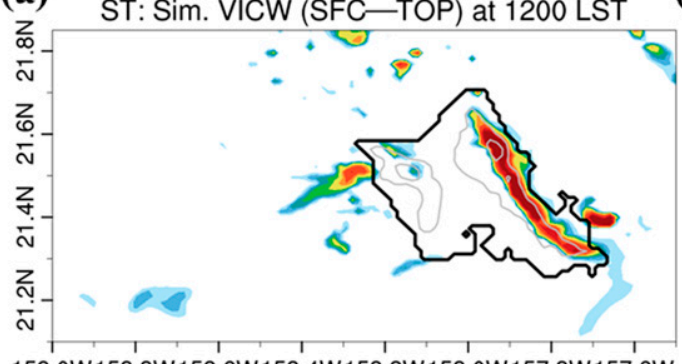

(b)

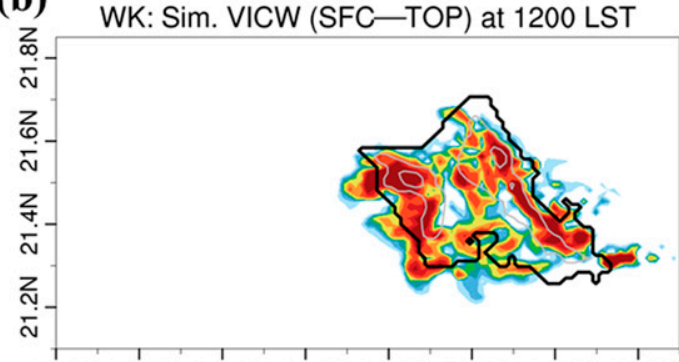

159.0W158.8W158.6W158.4W158.2W158.0W157.8W157.6W $159.0 \mathrm{~W} 158.8 \mathrm{~W} 158.6 \mathrm{~W} 158.4 \mathrm{~W} 158.2 \mathrm{~W} 158.0 \mathrm{~W} 157.8 \mathrm{~W} 157.6 \mathrm{~W}$

(c)

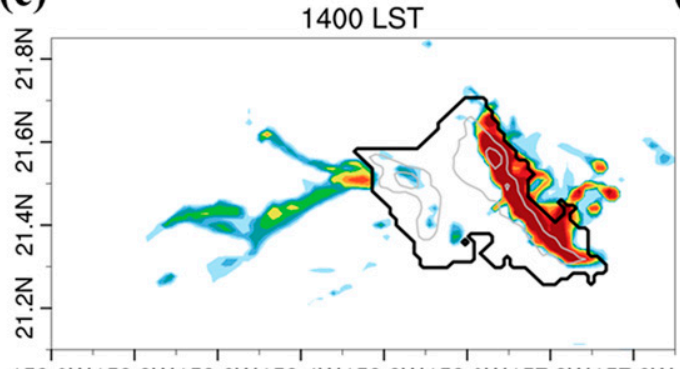

159.0W158.8W158.6W158.4W158.2W158.0W157.8W157.6W

(e)

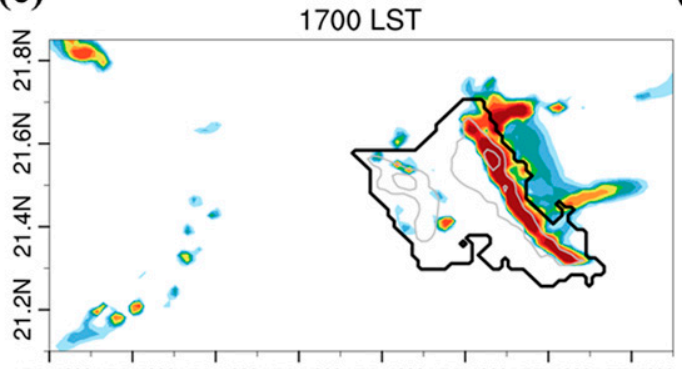

159.0W158.8W158.6W158.4W158.2W 158.0W $157.8 \mathrm{~W} 157.6 \mathrm{~W}$

ஸิ

(d)

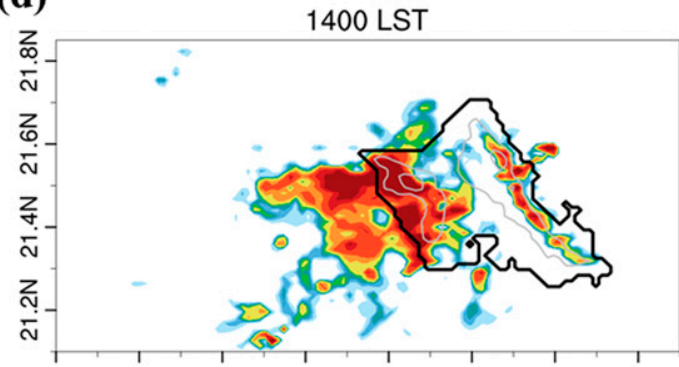

(f)

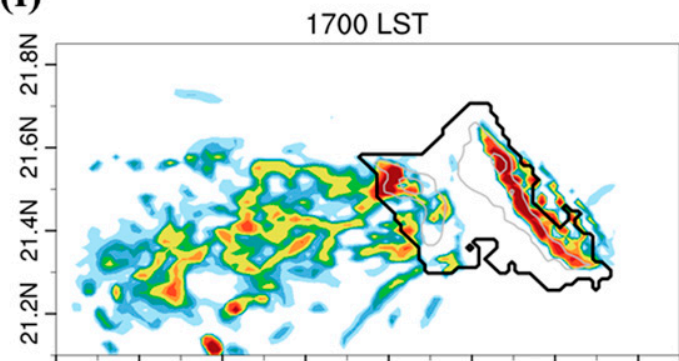

59.0W158.8W158.6W158.4W 158.2W $158.0 \mathrm{~W} 157.8 \mathrm{~W} 157.6 \mathrm{~W}$

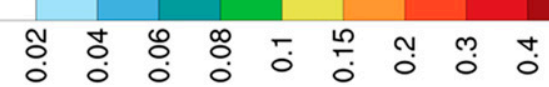

FIG. 20. Vertically integrated (from the surface to model top) cloud water (mm; shading) for strong trades at (a) 1200, (c) 1400, and (e) 1700 LST and for weak trades at (b) 1200, (d) 1400, and (f) 1700 LST.

Waianae Range and the western leeside slopes are smaller at 1400 LST and mostly disappear by 1700 LST (Figs. 16d,f). The high $\mathrm{RH}(>80 \%)$ layer around $1-2 \mathrm{~km}$ in height extends westward with time (Figs. 17b,d,f) as the maximum cloud water mixing ratio associated with orographic clouds above the Waianae Range drifts westward (Figs. 18b,d,f). Off the western leeside coast, westerly onshore flow in low levels brings cooler, moister maritime air toward the western leeside coast under weak trades (Figs. 16b, 17b, and 18b). At the $1500-\mathrm{m}$ level, a relatively cool $(<301.8 \mathrm{~K})$ and moist $(\mathrm{RH}>90 \%)$ area associated with orographic clouds over the Waianae Range and the leeside coast (Fig. 6b) is simulated at 1200 LST (Fig. 19b) under weak trades. This area continues to expand westward, over the wake zone, at 1400 LST (Fig. 19d) and extends farther downstream at 1700 LST (Fig. 19f) consistent with the simulated integrated cloud water (Figs. 20b,d,f) and satellite observations of cloudiness
(Fig. 6). These results suggest that the cloudiness in the wake zone during the afternoon hours comprising remnants of orographic clouds which have drifted westward under the influence of the combined eastward upper-level return flow, associated with the low-level leeside upslope flow, and the trade winds aloft (Figs. 18b,d,f).

Under strong trades, orographic lifting and descent of the easterly airflow are simulated over the windward and leeside slopes, respectively, of both the Koolau and Waianae Ranges with hydraulic jumps above the leeside slopes of both mountain ranges (Figs. 16a,c,e). Furthermore, the simulated cloud water is greater over the Koolau Range under stronger trades than weak trades due to stronger orographic lifting (Figs. 18a,c,e). At 1200 LST, weak rising motion is simulated over the leeside coast (Fig. 16a), resulting from the convergence between the onshore flow and downslope winds (Figs. 13a and 14a). Rising motions associated with 
(a) ST: Sim. hourly rainfall ending at 0500 LST

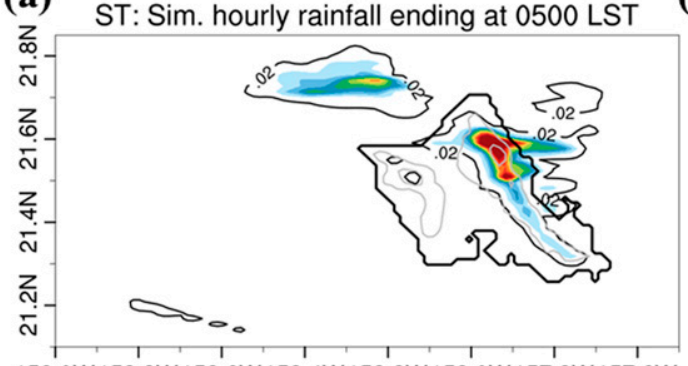

159.0W 158.8W158.6W 158.4W158.2W 158.0W157.8W157.6W

(c)

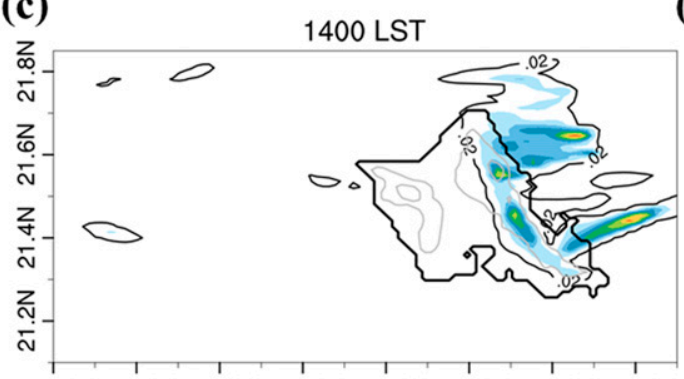

159.0W158.8W158.6W158.4W158.2W158.0W 157.8W157.6W

$\begin{array}{lllllllllll}0.1 & 0.2 & 0.3 & 0.4 & 0.5 & 0.6 & 0.7 & 0.8 & 0.9 & 1\end{array}$ (b)

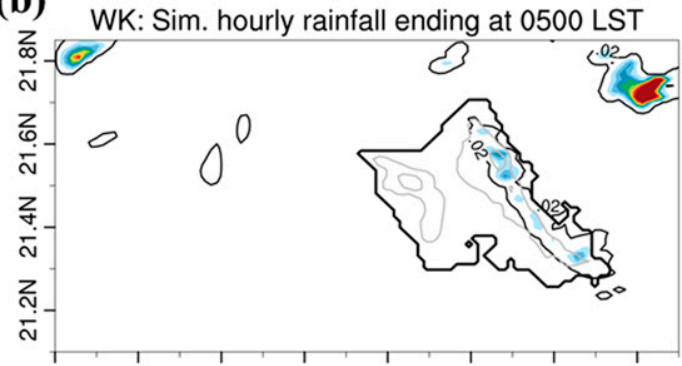

(d)

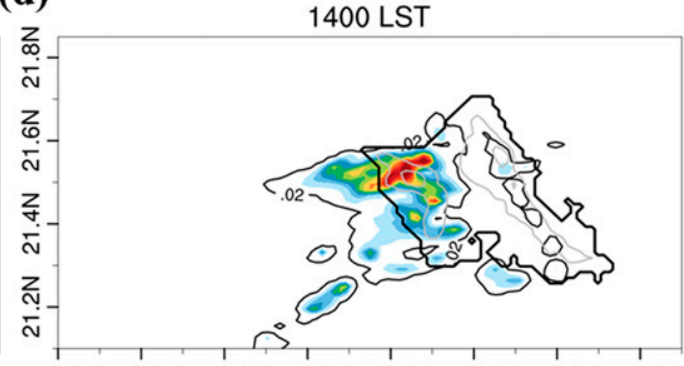

159.0W158.8W158.6W158.4W 158.2W 158.0W157.8W157.6W

$\begin{array}{lllllllllll}0.1 & 0.2 & 0.3 & 0.4 & 0.5 & 0.6 & 0.7 & 0.8 & 0.9 & 1\end{array}$

FIG. 21. Simulated hourly rainfall (mm) for strong trades at (a) 0500 and (c) 1400LST and for weak trades at (b) 0500 and (d) 1400 LST.

onshore flow are also simulated at 1400 LST (Fig. 16c), but disappear by 1700 LST (Fig. 16e). Under weak onshore flows at 1200 LST (Fig. 13a), only a very small afternoon cloud area is simulated (Fig. 18a), with an RH maximum $(>75 \%)$ in the $1-1.5 \mathrm{~km}$ layer off the leeside coast and maximum integrated cloud water extending offshore under strong trades. The development of cooler and moister onshore flow along the leeside coast is rather weak under strong trades (Fig. 17).

At the 1500-m height, significant warming (>304 K) and drying $(\mathrm{RH}<60 \%$ ) above the leeside slopes of both the Koolau and Waianae Ranges occur due to sinking motions associated with the mountain waves, with relatively moist and cooler air over the windward slopes under strong trades (Figs. 19a,c,e). In the wake zone, at 1200 and 1400 LST, a region of relatively high moisture $(>70 \%)$ and cool temperature $(<301.8 \mathrm{~K})$ extends westward and broadens from the leeside of Mount Kaala at 1700 LST (Figs. 19a,c). Nevertheless, the integrated cloud water over the Waianae Range is much less than during weak trades and is primarily found westward downstream of Mount Kaala. These results suggest that, similar to weak trades, the cloudiness in the wake zone under strong trades is thermally driven, but that this mechanism is much less effective in producing clouds than during weak trades.

Over the Koolau Range, orographic precipitation is greater during strong trade wind days $\left(>0.6 \mathrm{~mm} \mathrm{~h}^{-1}\right)$ than during weak trade wind days $\left(\sim 0.1 \mathrm{~mm} \mathrm{~h}^{-1}\right)$ (Fig. 21). Under strong trades, the early morning rainfall is greater

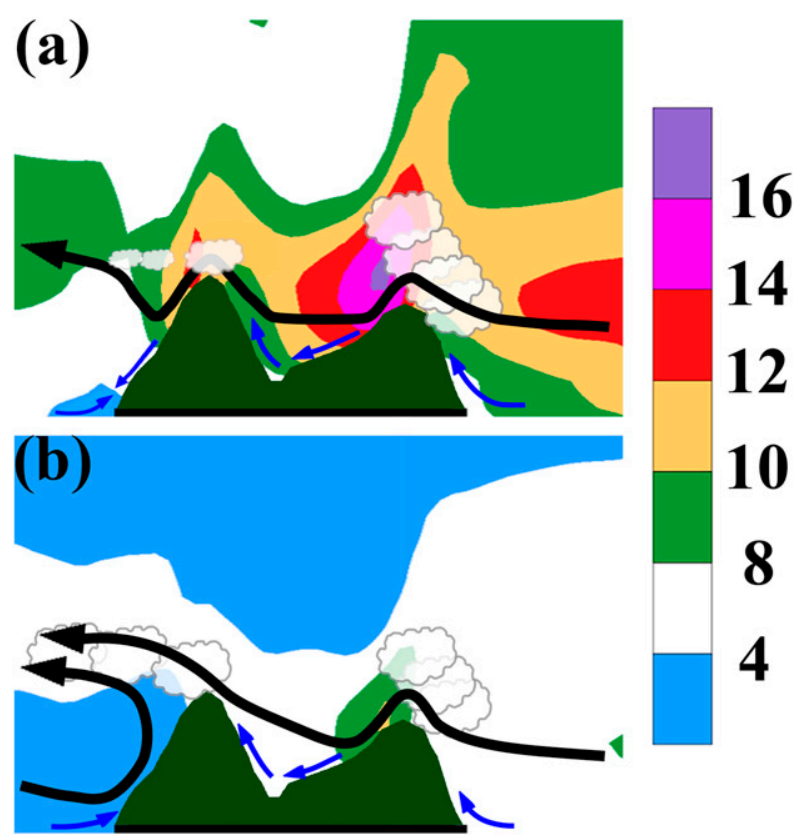

FIG. 22. A schematic diagram of the cloud formations at 1400 LST over Oahu under (a) strong trade wind and (b) weak trade wind conditions. Color shading represents horizontal wind speed $\left(\mathrm{m} \mathrm{s}^{-1}\right)$, black arrows represent the mean streamline above the mountaintops, and blue arrows represent surface wind. 

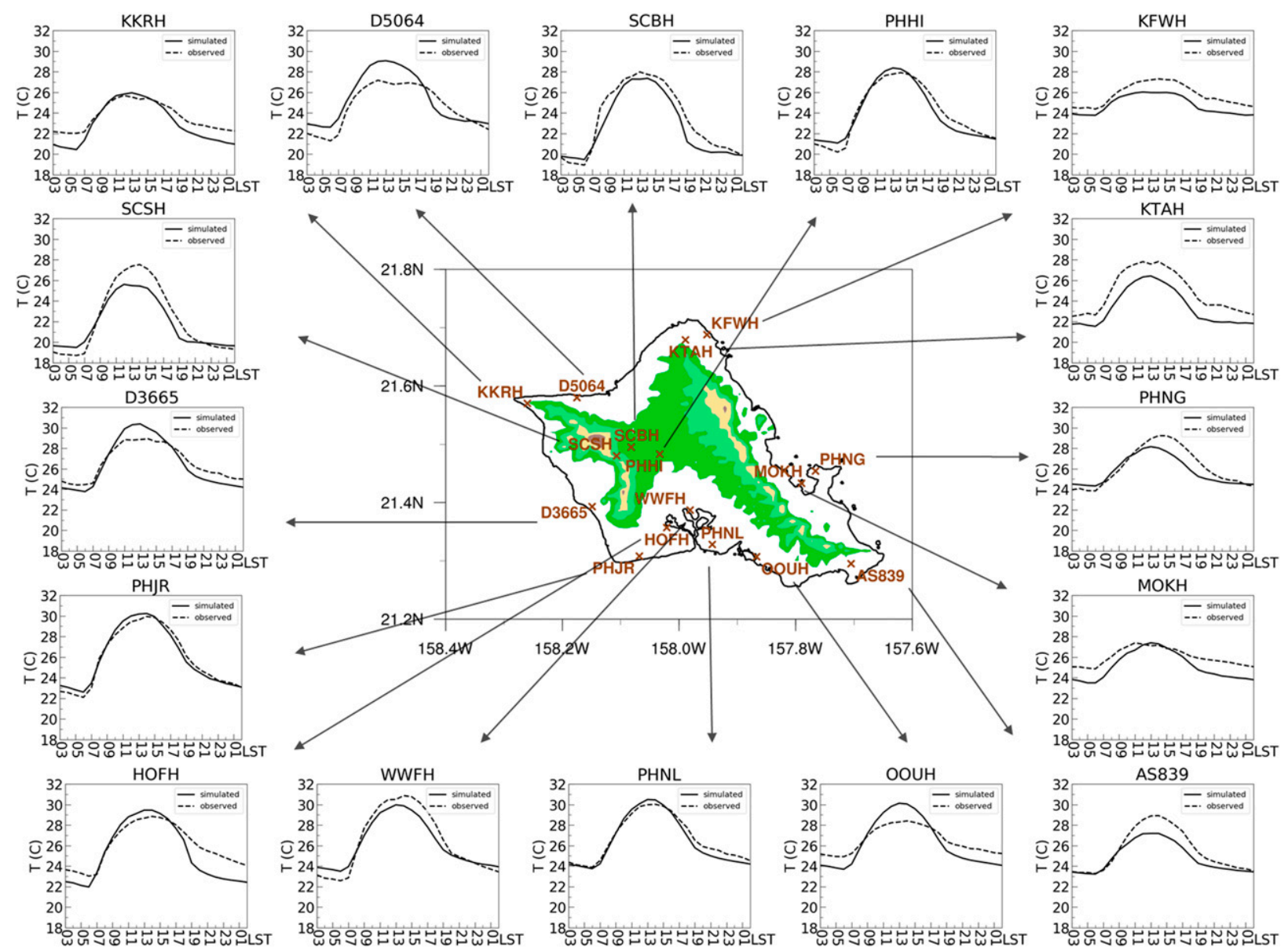

FIG. A1. Observed (dashed line) and simulated (solid line) diurnal variations of surface temperature $\left({ }^{\circ} \mathrm{C}\right)$ at various stations for JulAug 2013.

due to more significant orographic lifting (Figs. 10a,b) with much higher moisture content (Figs. 11a,b) when the land surface is the coldest (Fig. 21a). Over the Waianae Range, sea breezes develop along the Waianae coast, especially under weak trades, possibly resulting in light afternoon rainfall (Figs. 21c,d). The simulated diurnal variations of rainfall are consistent with previous observational (Hartley and Chen 2010) and modeling (Van Nguyen et al. 2010) studies. The results of the numerical simulations and satellite data are used to produce a schematic diagram of the Oahu cloud climatology in the afternoon (Fig. 22) under different trade wind conditions.

\section{Summary}

The trade wind strength has a significant impact on the island-scale airflow and cloudiness over the island of Oahu and its western leeside wake zone. We confirm the results of Yang et al. (2008b,c), namely that the warm advection from the island interior to the wake zone in the afternoon hours induces convergent airflow off the leeside coast. However, the Waianae Range, with peaks $\sim 1227 \mathrm{~m}$ above the leeside coast, produces significant drying and warming associated with descending airflow, which occurs particularly under stronger trades. Thus, the conditions in the wake zone are unfavorable for the development of convective clouds. We show that the cloudiness in the Oahu leeside wake zone under summer trade wind conditions is thermally driven, more significant under weak trades, and comprises the remnants of clouds which develop over the Waianae Range and are carried westward by winds aloft.

After sunrise, clouds on the windward side of the Koolau Range are caused by orographic lifting of the combined decelerated trade wind-anabatic flow. These clouds are more extensive on the windward side of the Koolau Range when trades are stronger, and drift westward downstream by the trade wind flow aloft.

With continued solar heating after sunrise, orographic clouds increase over the Waianae Range and along the western leeside coast, especially under weak trade wind conditions. Under weak trades, in addition to the upslope flow on the eastern slopes, the land-sea thermal contrast is critical to leeside circulations and the development of 

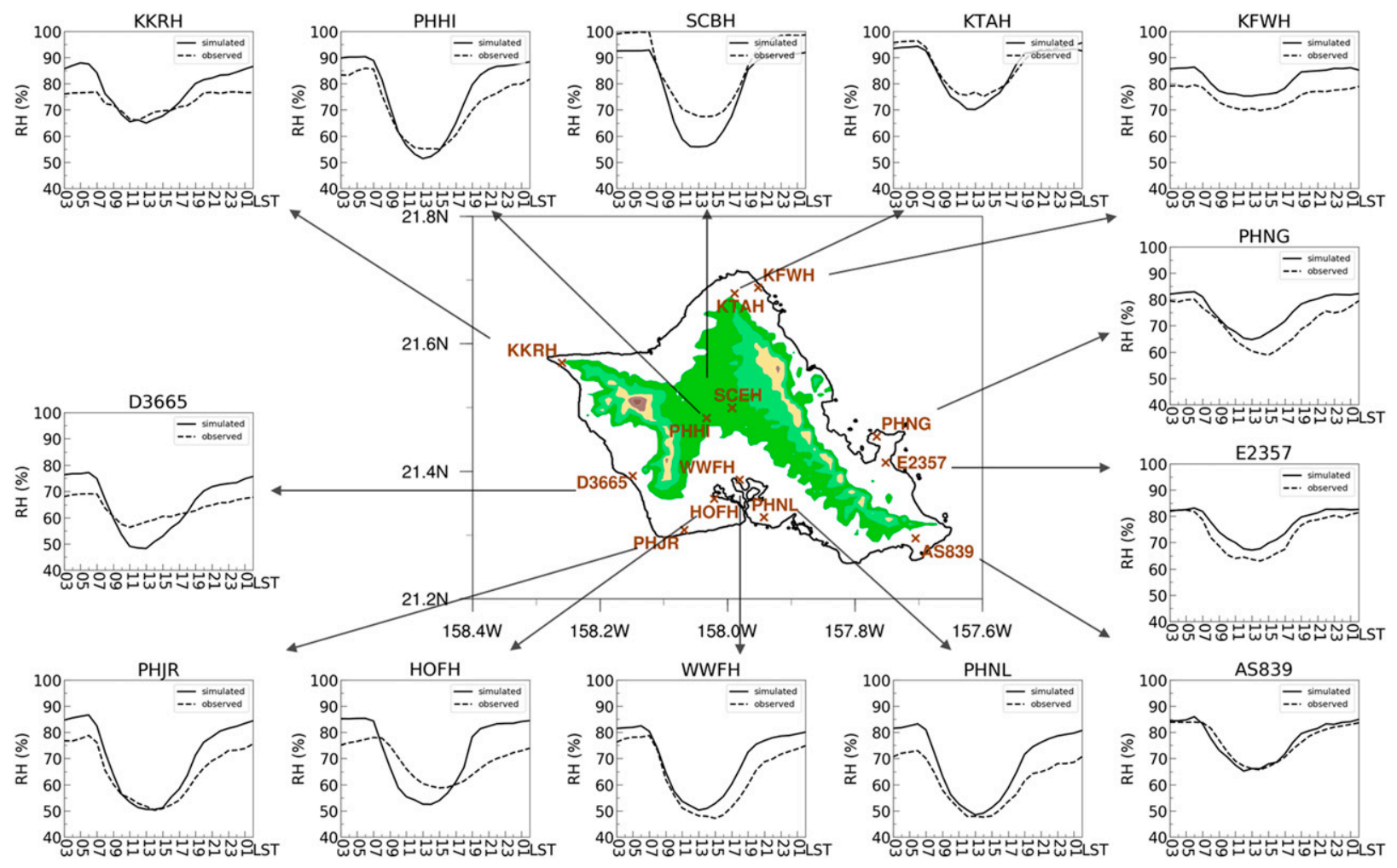

FIG. A2. As in Fig. A1, but of surface relative humidity (\%).

orographic clouds over the Waianae Range and in the wake zone in the afternoon. A westerly upslope/sea-breeze flow develops over the western leeside coast during the afternoon hours due to this land-sea thermal contrast. The westerly flow over the wake zone brings in maritime air along the coast and up the western slopes of the Waianae Range. Furthermore, with less moisture removal by orographic precipitation over the Koolau Range under weaker trades, orographic clouds form over the eastern slopes as well as over the leeside slopes of the Waianae Range. The sum total of these clouds are advected westward by the combined trade wind-easterly return flow above the mountaintops. Clouds off the leeside coast are most prevalent with the greatest horizontal extent in the afternoon hours, especially under weak trade wind conditions. These clouds are remnants of orographic clouds from the Waianae Range and are not generated over the leeside convergent zone as occurs off the leeside coast of the Big Island (Smith and Grubišic' 1993; Yang and Chen 2003).

With stronger trade wind speed, the airflow goes over the Koolau and Waianae Ranges with significant upslope and downslope winds and hydraulic jumps, especially in the early morning hours. The wake zone is drier and warmer under strong trades due to adiabatic warming on the leeside of the Waianae Range and warm-air advection by the easterly trade winds. With relatively weak moist onshore flow along the leeside coast and removal of moisture by precipitation over the Koolau Mountain Range, orographic clouds form less frequently over the mountaintops of the Waianae Range during the daytime, with fewer clouds offshore in the wake zone in the late afternoon, during strong trades.

Acknowledgments. This study was funded by the National Science Foundation under Grant AGS-1142558. This work was also partially funded by the OIA under Grant TAP-PacIOOS2018-5 and COMET/UCAR under Grant SUBAWD001374. The publication cost is funded by NSF under Grant AGS1854443, and Naval Facilities Engineering Command with funds through the Applied Research Laboratory at the University of Hawai'i at Manoa. Constructive suggestions by the editors, Dr. Stan Trier, and anonymous reviewers have greatly helped to improve the manuscript. We thank May Izumi for editing the text.

Data availability statement. The CFSv2 operational model data are obtained from the Research Data Archive (https:// doi.org/10.5065/D61C1TXF). The GOES-15 data are downloaded from the Comprehensive Large Array-data Stewardship System (CLASS, https://www.bou.class.noaa.gov/saa/products/ welcome). Surface observations are downloaded from MesoWest (https://mesowest.utah.edu/). The NCAR Command Language (http://dx.doi.org/10.5065/D6WD3XH5) is used for the composite analysis and visualizations in this paper. The model data are available upon request. 

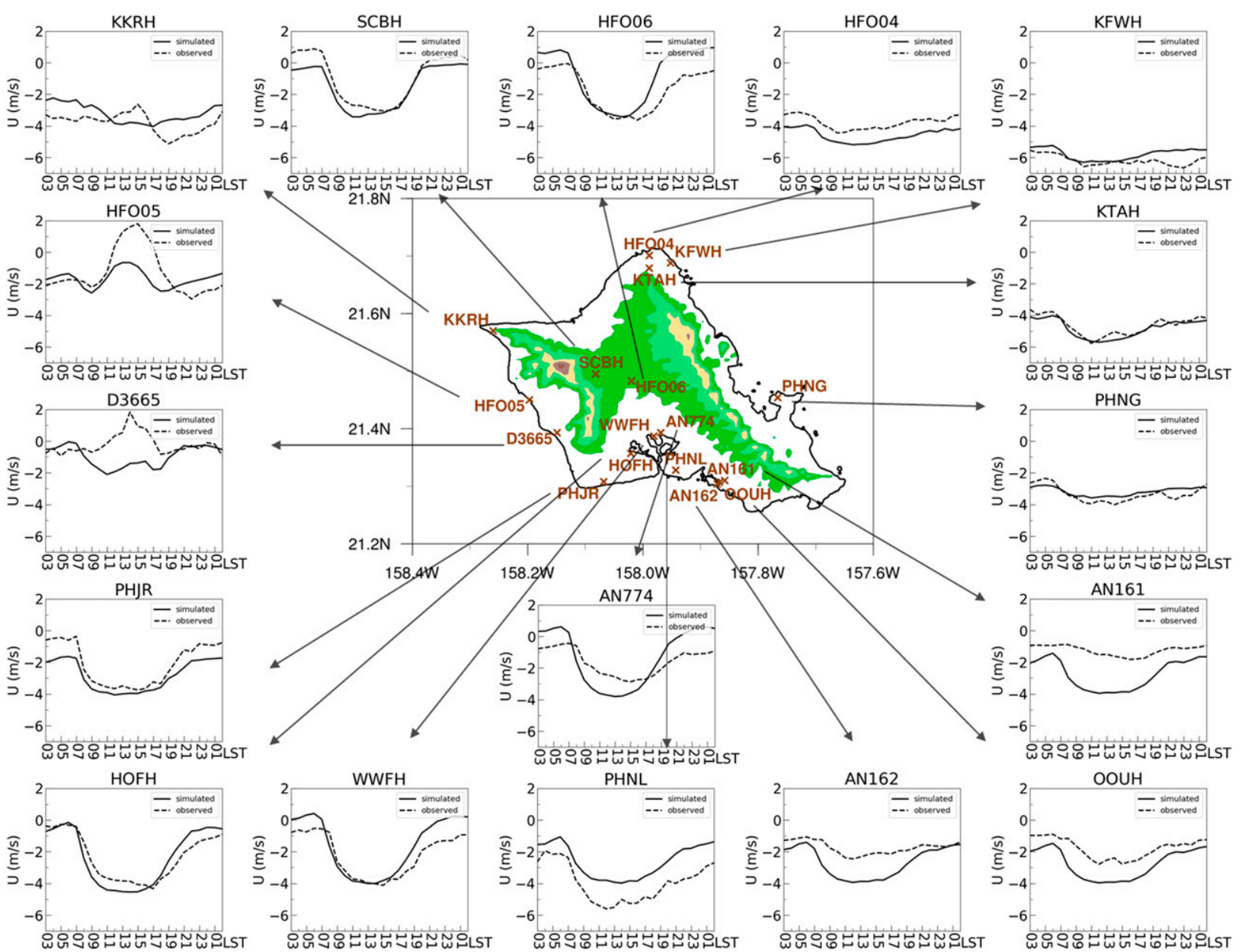

FIG. A3. As in Fig. A1, but of surface zonal wind $\left(\mathrm{m} \mathrm{s}^{-1}\right)$.

\section{APPENDIX}

\section{Diurnal Variations of Surface Temperature, Surface Relative Humidity, and Surface Wind at Various Stations}

Under trade wind conditions, composite surface temperature, surface $\mathrm{RH}$, and surface wind show significant diurnal variations (Figs. A1-A4 ). For stations along the eastern coast (KTAH, KFWH, PHNG, MOKH, E2357, and AS839), the diurnal ranges in the surface air temperature and $\mathrm{RH}$ are smaller than for stations in the island interior and on the leeside coasts, with higher nighttime minimum air temperature and $\mathrm{RH}$ and cooler and moister air in the afternoon (Figs. A1 and A2). Stations along the southern coast (WWFH, PHNL, HOFH, OOUH, and PHJR) and central valley (SCBH, SCEH, and PHHI), especially those in areas with urban land use, have the largest diurnal range in surface air temperature and moisture (Figs. A1 and A2).

Similarly, winds along the windward coastal areas, which are well exposed to the incoming trades, have smaller diurnal variations as compared to other stations (Figs. 2, A3, and A4). Over the central Oahu plain, winds are affected by the mountain-valley wind circulations associated with both mountain ranges due to the diurnal heating cycle. Stations along the south shore have the largest diurnal variations with warmer temperatures, less humidity, and higher wind speed during the daytime and cooler temperatures, more humidity, and often light to calm winds at night. For the stations along the western coasts (HFO05 and D3665), westerly sea breezes are observed during the afternoon hours. However, although sea breezes are simulated in general along the western leeside coast (Fig. 13), they are not simulated at these two sites despite the fact that the simulated surface temperature is consistent with observations. One possible reason for this is that the peak of the Waianae Range is $887 \mathrm{~m}$ in the $1.5-\mathrm{km}$ model grid, which is substantially lower than the actual height of the highest peak $(1227 \mathrm{~m})$. The deficiency in height may cause the orographic blocking on the eastern slope to be less significant than actually exists allowing the trade wind flow to move over the mountaintops, resulting in weak easterly offshore flow in the simulation during the afternoon hours. In general, the simulation depicts diurnal variations that 

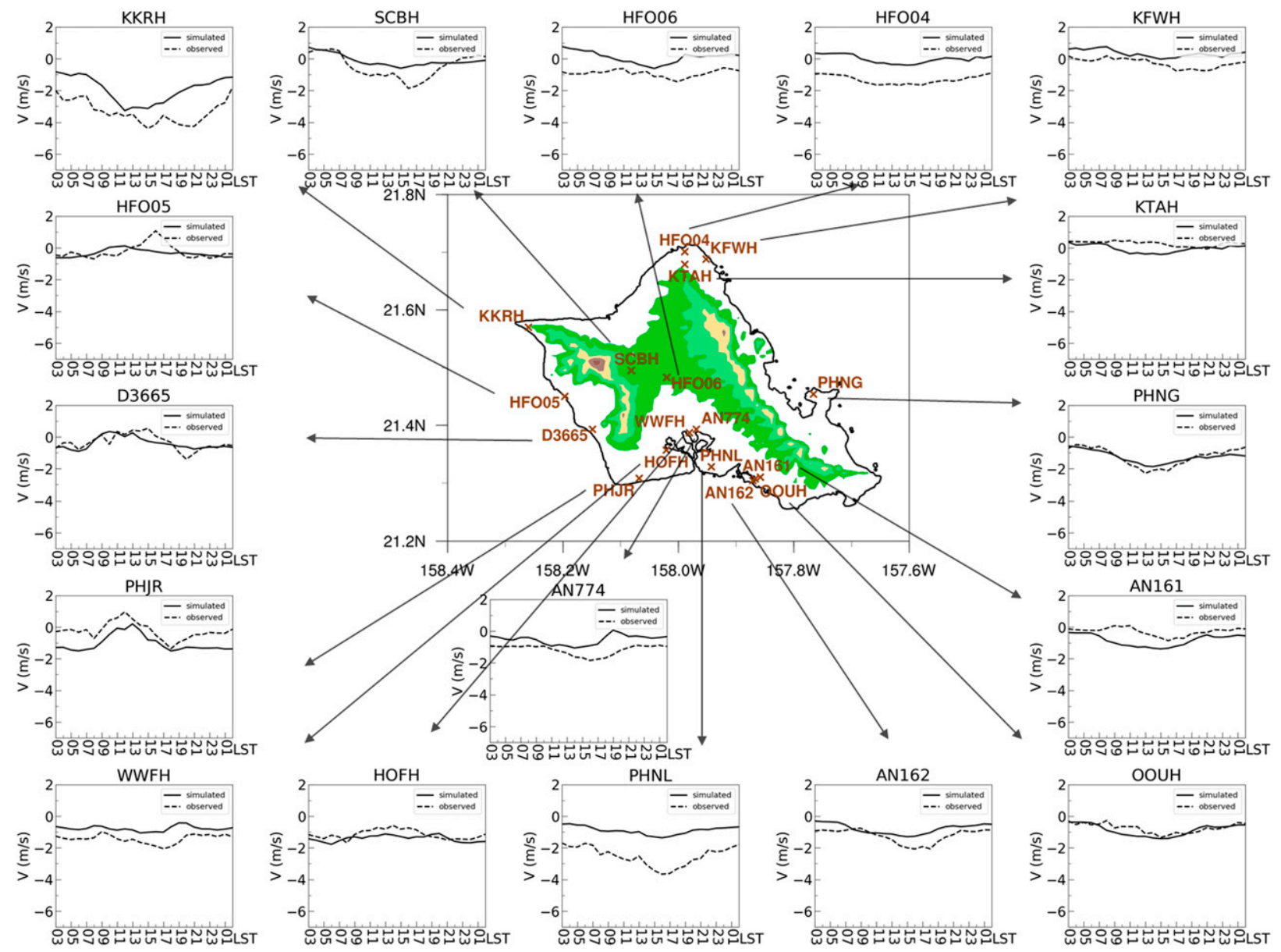

FIG. A4. As in Fig. A1, but of surface meridional wind $\left(\mathrm{m} \mathrm{s}^{-1}\right)$.

are in reasonable agreement with observations at most stations.

\section{REFERENCES}

Bradshaw, L. S., G. Petrescu, and, 2003: An initial analysis of relationships between 2- and 10-minute averaged winds at 10 , 6, and 1.8 meters: Implications for fire behavior and danger applications. Preprints, Fifth Symp. on Fire and Forest Meteorology, Orlando, FL, Amer. Meteor. Soc., 4.2, http:// ams.confex.com/ams/pdfpapers/65901.pdf.

Chen, F., and J. Dudhia, 2001: Coupling an advanced land surfacehydrology model with the Penn State/NCAR MM5 modeling system. Part I: Model implementation and sensitivity. Mon. Wea. Rev., 129, 569-585, https://doi.org/10.1175/15200493(2001)129<0569:CAALSH>2.0.CO;2.

Chen, Y.-L., and J. Feng, 2001: Numerical simulations of airflow and cloud distributions over the windward side of the island of Hawaii. Part I: The effects of trade wind inversion. Mon. Wea. Rev., 129, 1117-1134, https://doi.org/10.1175/1520-0493(2001) $129<1117$ :NSOAAC $>2.0 . \mathrm{CO} ; 2$.

Crook, N. A., 2001: Understanding Hector: The dynamics of island thunderstorms. Mon. Wea. Rev., 129, 1550-1563, https://doi.org/10.1175/1520-0493(2001)129<1550:UHTDOI> 2.0.CO;2.
Dorman, C. E., 1994: Guadalupe Island cloud trail. Mon. Wea Rev., 122, 235-242, https://doi.org/10.1175/1520-0493(1994) $122<0235$ :GICT $>2.0 . \mathrm{CO} ; 2$.

Dudhia, J., 1989: Numerical study of convection observed during the Winter Monsoon Experiment using a meso-scale twodimensional model. J. Atmos. Sci., 46, 3077-3107, https://doi.org/ 10.1175/1520-0469(1989)046<3077:NSOCOD >2.0.CO;2.

Foote, D. E., E. L. Hill, S. Nakamura, and F. Stephens, 1972: Soil survey of islands of Kaua'i, O'ahu, Maui, Moloka'i, and Lanai, State of Hawai'i. Soil Conservation Service, U.S. Department of Agriculture, in cooperation with the University of Hawai' $i$ Agricultural Experiment Station, 115 pp. [Available from Natural Resources Conservation Service, U.S. Department of Agriculture, Rm. 4-118, 300 Ala Moana Blvd., Honolulu, HI 96850].

Hartley, T., and Y.-L. Chen, 2010: Characteristics of summer trade wind rainfall over Oahu. Wea. Forecasting, 25, 1797-1815, https://doi.org/10.1175/2010WAF2222328.1.

Hitzl, D. E., Y.-L. Chen, and H. V. Nguyen, 2014: Numerical simulations and observations of airflow through the 'Alenuihāhā Channel, Hawaii. Mon. Wea. Rev., 142, 4696-4718, https://doi.org/ 10.1175/MWR-D-13-00312.1.

Hong, S.-Y., and J.-O. J. Lim, 2006: The WRF single-moment 6-class microphysics scheme (WSM6). J. Korean Meteor. Soc., 42, 129-151. 
—, Y. Noh, and J. Dudhia, 2006: A new vertical diffusion package with an explicit treatment of entrainment processes. Mon. Wea. Rev., 134, 2318-2341, https://doi.org/10.1175/ MWR3199.1.

Horel, J., and Coauthors, 2002: MesoWest: Cooperative mesonets in the western United States. Bull. Amer. Meteor. Soc., 83, 211-225, https://doi.org/10.1175/1520-0477(2002)083<0211: MCMITW $>2.3 . \mathrm{CO} ; 2$.

Hsiao, F., Y.-L. Chen, and D. E. Hitzl, 2020: Heavy rainfall events over central Oahu under weak wind conditions during seasonal transitions. Mon. Wea. Rev., 148, 4117-4141, https:// doi.org/10.1175/MWR-D-19-0358.1.

Hudson, J. G., 1993: Cloud condensation nuclei. J. Appl. Meteor., 32, 596-607, https://doi.org/10.1175/1520-0450(1993)032<0596: $\mathrm{CCN}>2.0 . \mathrm{CO} ; 2$.

Janjić, Z. I., 1994: The step-mountain eta coordinate model: Further developments of the convection, viscous sublayer, and turbulence closure schemes. Mon. Wea. Rev., 122, 927-945, https://doi.org/10.1175/1520-0493(1994)122<0927:TSMECM> 2.0.CO;2.

- 2000: Comments on "Development and evaluation of a convection scheme for use in climate models." J. Atmos. Sci., 57, 3686, https://doi.org/10.1175/1520-0469(2000)057<3686: CODAEO $>2.0 . \mathrm{CO} ; 2$.

Jiménez, P. A., J. Dudhia, J. F. González-Rouco, J. Navarro, J. P. Montávez, and E. García-Bustamante, 2012: A revised scheme for the WRF surface layer formulation. Mon. Wea. Rev., 140, 898-918, https://doi.org/10.1175/MWR-D-1100056.1.

Johnston, C. M., C. E. Holloway, and R. S. Plant, 2018: Cloud trails past Bermuda: A five-year climatology from 2012 to 2016. Mon. Wea. Rev., 146, 4039-4055, https://doi.org/10.1175/ MWR-D-18-0141.1.

Jury, M., and S. Chiao, 2013: Leeside boundary layer confluence and afternoon thunderstorms over Mayaguez, Puerto Rico. J. Appl. Meteor. Climatol., 52, 439-454, https://doi.org/ 10.1175/JAMC-D-11-087.1.

Kirshbaum, D. J., and J. G. Fairman Jr., 2015: Cloud trails past the Lesser Antilles. Mon. Wea. Rev., 143, 995-1017, https:// doi.org/10.1175/MWR-D-14-00254.1.

Leopold, L. B., 1948: Diurnal weather patterns on O'ahu and Lanai, Hawai'i. Pac. Sci., 2, 81-95.

Li, L., and Y.-L. Chen, 2017: Numerical simulations of two trapped mountain lee waves downstream of Oahu. J. Appl. Meteor. Climatol., 56, 1305-1324, https://doi.org/10.1175/JAMC-D-150341.1.

Malkus, J. S., 1963: Tropical rain induced by a small heat source. J. Appl. Meteor., 2, 547-556, https://doi.org/10.1175/15200450(1963)002<0547:TRIBAS $>2.0$.CO;2.

— over Nantucket island during the summer of 1950. Papers in Physical Oceanography and Meteorology, Vol. XII, No. 2, Massachusetts Institute of Technology and Woods Hole Oceanographic Institution, $50 \mathrm{pp}$.

Mlawer, E. J., S. J. Taubman, P. D. Brown, M. J. Iacono, and S. A. Clough, 1997: Radiative transfer for inhomogeneous atmospheres: RRTM, a validated correlated-k model for the longwave. J. Geophys. Res., 102, 16663-16682, https://doi.org/ 10.1029/97JD00237.

NOAA, 2019: Coastal Change Analysis Program (C-CAP) regional land cover. NOAA/Office for Coastal Management, accessed March 2019, http://www.coast.noaa.gov/htdata/ raster1/landcover/bulkdownload/30m_lc/.
NOAA/CPC, 2020: Oceanic Niño Index (ONI). Accessed 6 October 2020, https://origin.cpc.ncep.noaa.gov/products/analysis_ monitoring/ensostuff/ONI_v5.php.

Nordeen, M. L., P. Minnis, D. R. Doelling, D. Pethick, and L. Nguyen, 2001: Satellite observations of cloud plumes generated by Nauru. Geophys. Res. Lett., 28, 631-634, https:// doi.org/10.1029/2000GL012409.

Reeve, M. A., and E. W. Kolstad, 2011: The Spitsbergen South Cape tip jet. Quart. J. Roy. Meteor. Soc., 137, 1739-1748, https://doi.org/10.1002/qj.876.

Saha, S., and Coauthors, 2011: NCEP Climate Forecast System Version 2 (CFSv2) 6-hourly products, continuing from January 2011 (updated daily). Research Data Archive at the National Center for Atmospheric Research, Computational and Information Systems Laboratory, accessed 5 April 2018, https://doi.org/10.5065/D61C1TXF.

Sato, H. H., W. Ikeda, R. Paeth, R. Smythe, and M. Takehiro Jr., 1973: Soil survey of the island of Hawai'i, State of Hawai'i. USDA/Soil Conservation Service and University of Hawai'i Agricultural Experiment Station, $232 \mathrm{pp}$.

Schroeder, T. A., 1981: Characteristics of local winds in northwest Hawaii. J. Appl. Meteor., 20, 874-881, https://doi.org/10.1175/ 1520-0450(1981)020<0874:COLWIN >2.0.CO;2.

Skamarock, W. C., and Coauthors, 2008: A description of the Advanced Research WRF version 3. NCAR Tech. Note NCAR/TN-475+STR, 113 pp., https://doi.org/10.5065/ D68S4MVH.

Smith, R. B., 1989: Mountain-induced stagnation points in hydrostatic flow. Tellus, 41A, 270-274, https://doi.org/10.1111/ j.1600-0870.1989.tb00381.x.

— and V. Grubišic', 1993: Aerial observation of Hawaii's wake. J. Atmos. Sci., 50, 3728-3750, https://doi.org/10.1175/15200469(1993)050<3728:AOOHW>2.0.CO;2.

Smolarkiewicz, P. K., R. M. Rasmussen, and T. L. Clark, 1988: On the dynamics of Hawaiian cloud bands: Island forcing. J. Atmos. Sci., 45, 1872-1905, https://doi.org/10.1175/15200469(1988)045<1872:OTDOHC > 2.0.CO;2.

Splitt, M. E., and J. D. Horel, 1998: Use of multivariate linear regression for meteorological data analysis and quality assessment in complex terrain. Preprints, 10th Symp. on Meteorological Observations and Instrumentation, Phoenix, AZ, Amer. Meteor. Soc., 359-362.

Van Nguyen, H. V., Y.-L. Chen, and F. M. Fujioka, 2010: Numerical simulations of island effects on airflow and weather during the summer over the island of Oahu. Mon. Wea. Rev., 138, 2253-2280, https://doi.org/10.1175/ 2009MWR3203.1.

Weinreb, M. P., M. Jamieson, N. Fulton, Y. Chen, J. X. Johnson, J. Bremer, C. Smith, and J. Baucom, 1997: Operational calibration of Geostationary Operational Environmental Satellite-8 and -9 imagers and sounders. Appl. Opt., 36, 68956904, https://doi.org/10.1364/AO.36.006895.

Winning, T., Y.-L. Chen, and F. Xie, 2017: Estimation of the marine boundary layer height over the central North Pacific using GPS radio occultation. Atmos. Res., 183, 362-370, https:// doi.org/10.1016/j.atmosres.2016.08.005.

Yang, Y., and Y.-L. Chen, 2003: Circulations and rainfall on the lee side of the island of Hawaii during HaRP. Mon. Wea. Rev., 131, 2525-2542, https://doi.org/10.1175/1520-0493(2003) $131<2525$ :CAROTL $>2.0$. CO; 2 .

, J. Ma, and S. Xie, 2008a: Observations of the trade wind wakes of Kauai and Oahu. Geophys. Res. Lett., 35, L04807, https://doi.org/10.1029/2007GL031742. 
- S.-P. Xie, and J. Hafner, 2008b: The thermal wake of Kauai Island: Satellite observations and numerical simulations. J. Climate, 21, 4568-4586, https://doi.org/10.1175/2008JCLI1895.1. $\ldots, \ldots$, and —_, 2008c: Cloud patterns lee of Hawaii Island: A synthesis of satellite observations and numerical simulation. J. Geophys. Res., 113, D15126, https://doi.org/10.1029/ 2008JD009889.

Zhang, Y., Y.-L. Chen, S.-Y. Hong, H.-M. H. Juang, and K. Kodama, 2005a: Validation of the coupled NCEP Mesoscale Spectral Model and an advanced land surface model over the Hawaiian Islands. Part I: Summer trade wind conditions and a heavy rainfall event. Wea. Forecasting, 20, 847-872, https://doi.org/10.1175/WAF891.1.

, _ - and K. Kodama, 2005b: Validation of the coupled NCEP Mesoscale Spectral Model and an advanced land surface model over the Hawaiian Islands. Part II: A high wind event. Wea. Forecasting, 20, 873-895, https://doi.org/10.1175/ WAF892.1.

, T. A. Schroeder, and K. Kodama, 2005c: Numerical simulations of sea-breeze circulations over northwest Hawaii. Wea. Forecasting, 20, 827-846, https://doi.org/10.1175/ WAF859.1. 